\title{
الحدود المناخية لزراعة وإنتاج النخيل في محافظة واسط
}

$$
\text { م·م. انتصار سكر خيون }
$$

جامعة ذي قار -كلية التربية -قسم الجغرافية

المقدمة: - ا

حظيت أنشار النخيل والزيتون بالعناية والذكر والاهتمام على مر العصور وفي الحضارات والأديان

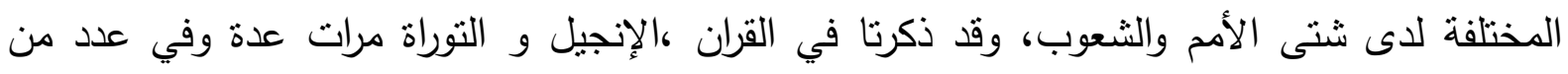

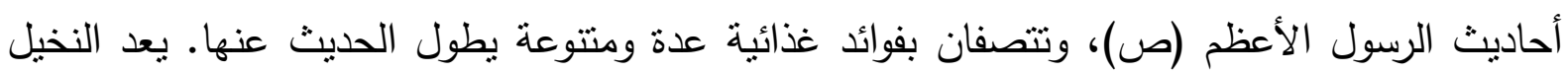

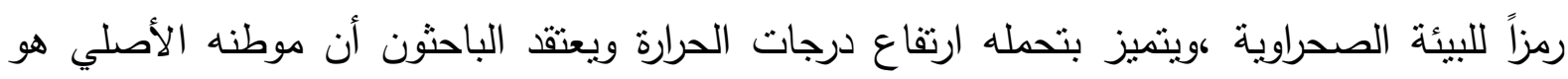
الخليج العربي باعنباره منطقة شبه استوائية.

تتجسد مشكلة البحث بالسؤال الاتي(ما علاقة عناصر المناخ بتحديد زراعة وأتناج النخيل في محافظة واسط؟)، أما فرضية البحث فتتمثل ب(يعد المناخ عاملا محددا لزراعة وإنتاج النخيل في محافظة

المنطلبات المناخية لزراعة أشجار النخيل:

$$
\text { أولا :- الضوء }
$$

يعد ضوء الثمس ضرورة ينطلبها النبات في كل مرحلة من مراحل نموه ،كونه مهما في توفير الطاقة

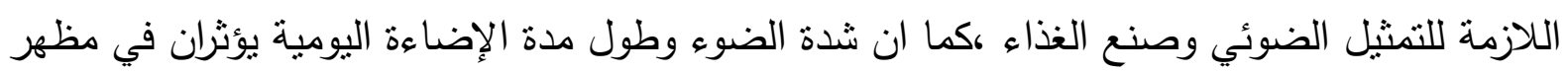

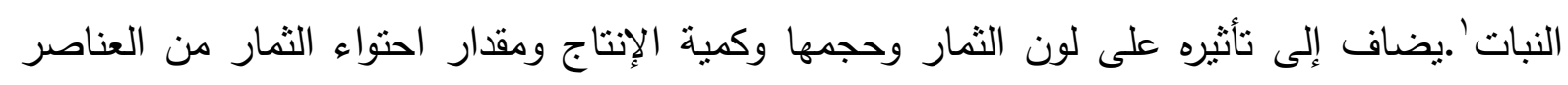

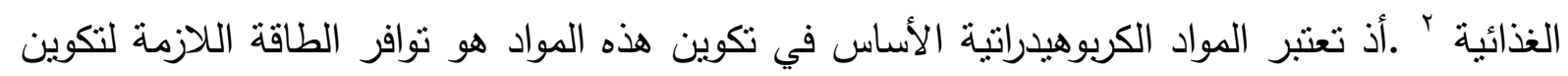

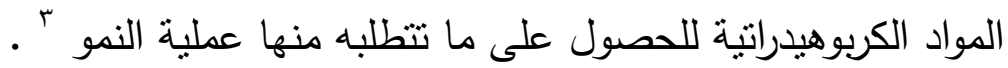


ولكل نوع من النبات حدود عليا ودنيا من الضوء إذ المقدرة على النمو في ضمن هذه الظروف أي الحدود التي يستطيع فيها النبات وبهذا المقدار من الضوء يمكن القيام بإنتاج المواد الغذائية التي يحتاجها وفي ضمن المدة المعينة من نمو النبات، ففي مدة الأزهار تحتاج إلى ضوء أكثر من فترات النمو الاعتيادية ـ وفي التربة الفقيرة يحتاج النبات إلى كمية من الضوء أكثر من البيئات التي تكون تربتها

غنية بالمواد المعدنية التي يحتاجها النبات ؛

ضوء الثمس من عناصر المناخ الضرورية لنجاح زراعة النخيل وإنتاج التمور • فالنمو الطبيعي للنخلة الذي يظهر في استطالة سعف قمنها يحدث غالبا ما بين شروق الثمس وغروبها فاذا زرعت النخلة في الظل فأن نموها لا يكون طبيعيا حتى في أثند المناطق حرارة ،وذلك لان سعفها الأخضر لا يقوم بوظيفته ألا أذا تعرض لأشعة الثمس المباشرة والمناطق التي يكثر انحجاب الثمس فيها لا تصلح لزراعة النخيل '• ويوثر الضوء على كمية المواد الغذائية التي تحصل عليها النخلة لأنه يدخل عنصراً رئيسيا في عملية صنعها ،ويعد الضوء عاملا مهما لإكمال نمو النخيل وذلك لأهميته في تحديد نسب السكر والحوامض والمواد القابضة واللون لثمرة النخلة ،فضلا عن ذلك يكون نمو الثجرة غير طبيعي عند زراعتها في المناطق التي يقل فيها الإشعاع الثمسي • لان أفضل مدة لنمو سعف النخلة تكون ما بين مدة شروق الثمس وغروبها وغالبا ما يبطأ نمو السعف في الأيام الغائمة `. أذ نتأثز إنتاجية النخلة بالموجات القصيرة والمتوسطة من موجات الطيف الثمسي والتي تتحصر ما بين اللون البنفسي(ץ , • ميكرون واللون الأصفر(T, • )ميكرون ^، ويبرز تأثثر الضوء على عملية التزهير ما بين شهري أذار -نيسان تقريبا وذلك لتساوي ساعات النهار والليل في هذين الثهرين ،اذ تستطيع أزهار النخيل الحصول على كميات جديدة من الضوء وأثنعة الثمس ،وأخيرا نساعد النخلة على أنمام دورة حياتها المختلفة من نمو خضري وتزهير وأثمار '.وكلما تقدمت ثمرة النخلة بالنمو تحتاج إلى فترات ضوئية اكثر ولاسيما في شهري حزيران و تموز • إذ أن لطول النهار دوراً مهماً في تزايد مدة الإشعاع الثمسي (الضوئي)فضلا عن أنه يساعد على سرعة التغيرات الكيمياوية والفيزيائية لثمار النخيل وسرعة تحوله من طور إلى أخر ومن ثم نضجه. 


\section{ثانيا:- الحدود الحرارية}

تتسم الحرارة بانها من أكثر الظواهر المناخية التي تؤثر على توزيع النباتات ولاسيما على المستوى

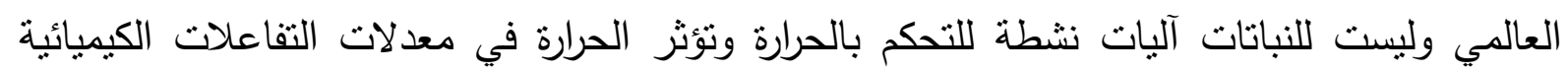

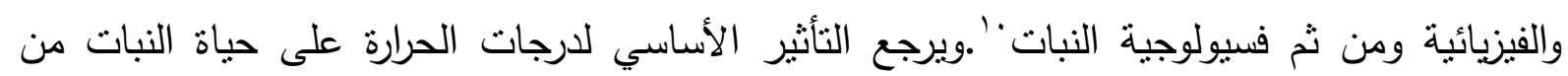

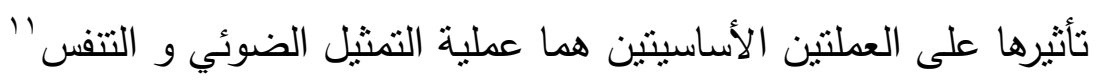

$$
\text { 1 - الحدود الحرارية المنلى لزراعة النخيل }
$$

الحدود الحرارية المنلى هي التي يحقق النبات فيها أعلى مستوى من النمو والازدهار والأثمار

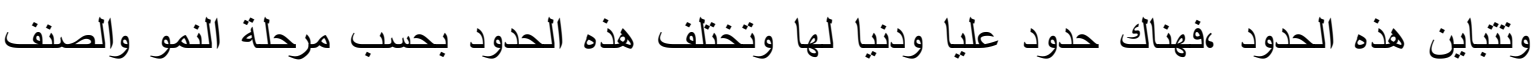

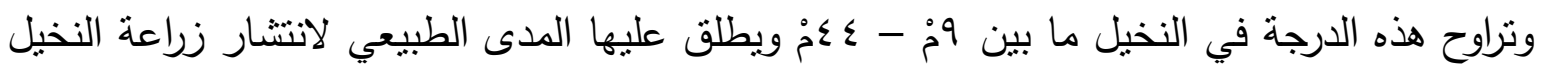

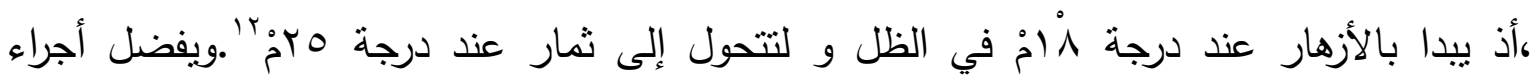

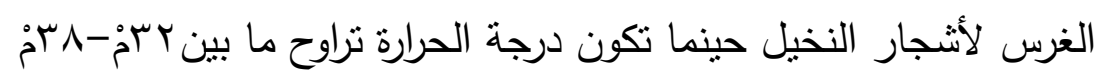

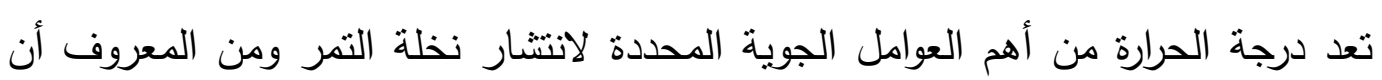

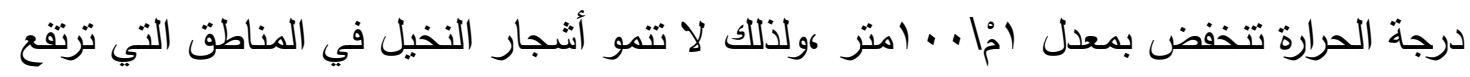

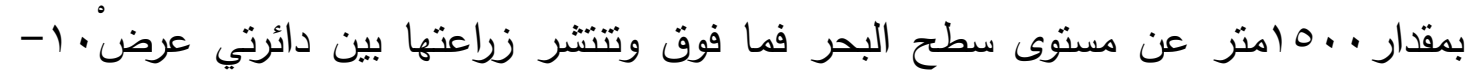

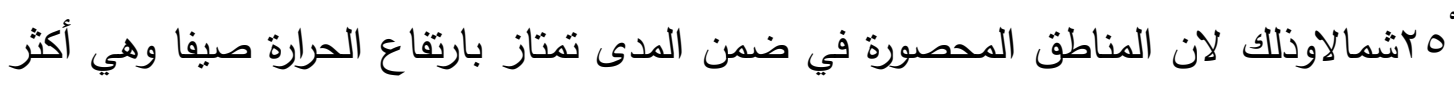

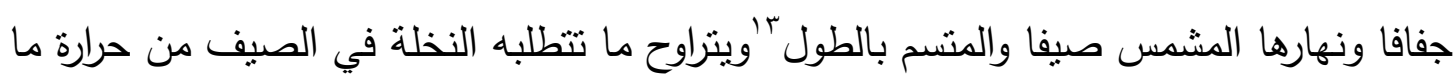

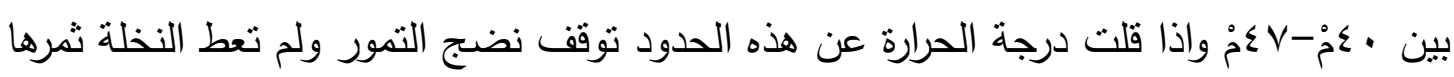

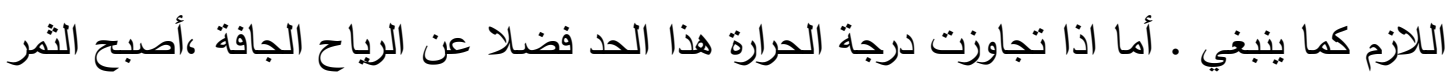

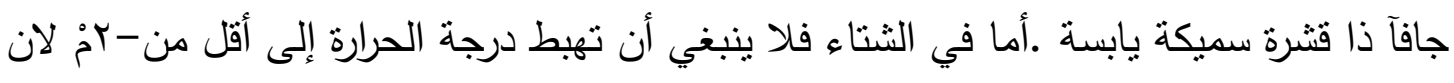
النخلة لا تقوى على مقاومة البرد الثديد. 
r- الحدود الحرارية العليا لزراعة النخيل

تمثل الحدود الحرارية العليا الحد الأعلى الذي يتحمله النبات وبتزايدها يتوال نمو الحد الأعلى لفيل

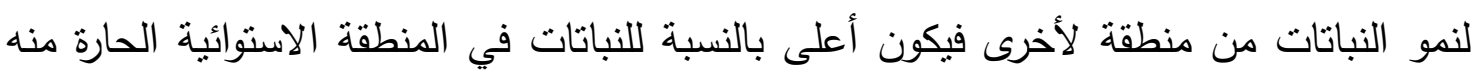

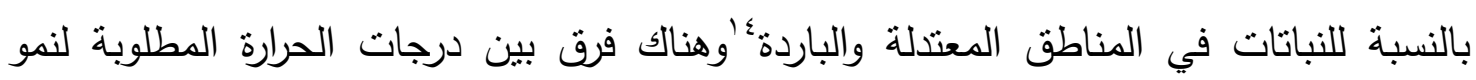

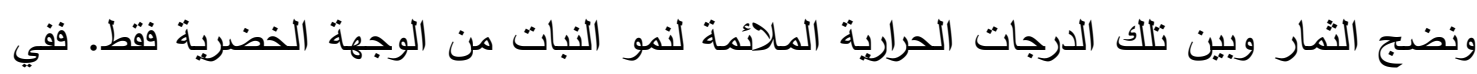

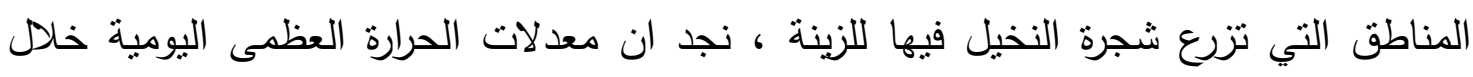

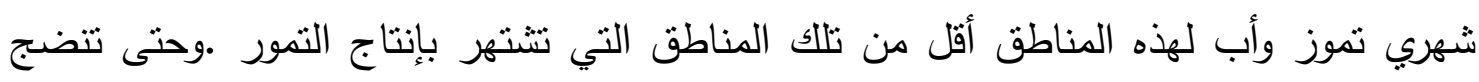

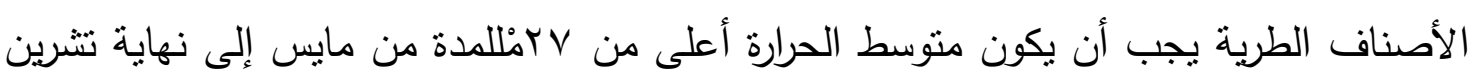

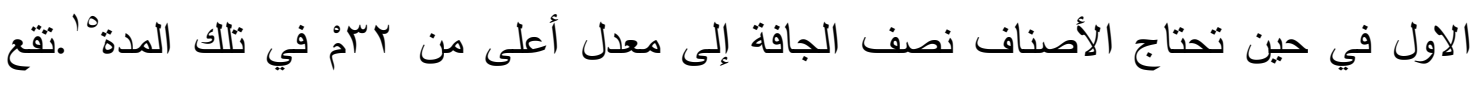

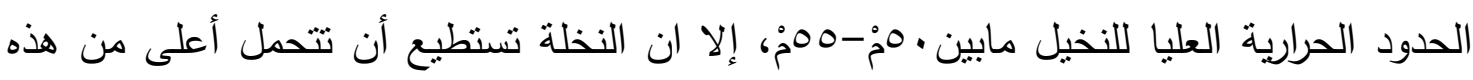

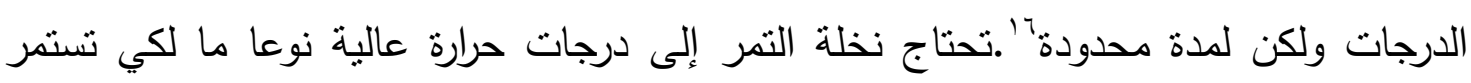

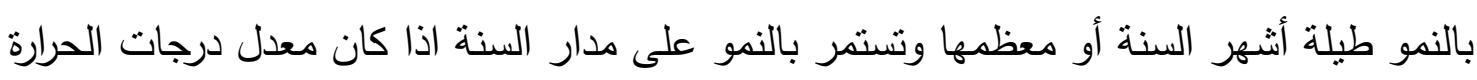

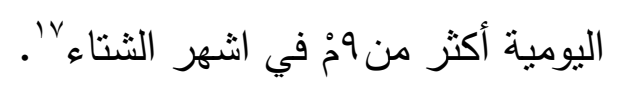

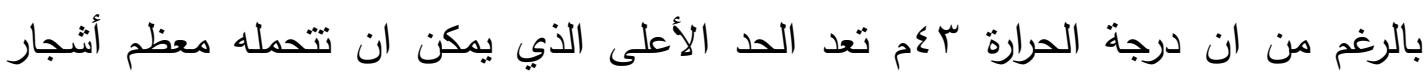

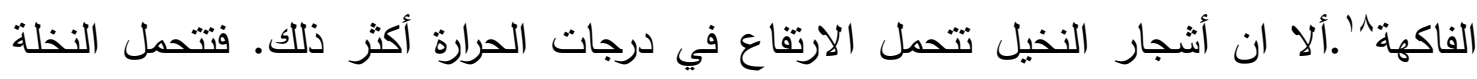

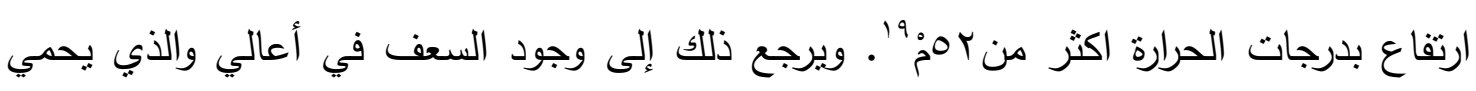
الجمارة من ارتفاع درجة حرارة الهواء المحيط بها. تتعرض النخلة لأضرار خطيرة اذا ما تجاوزت الحرارة الحدود الحرارية العليا التي يمكن للنخيل

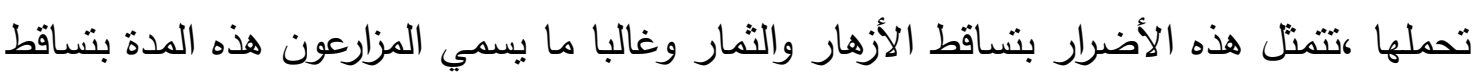

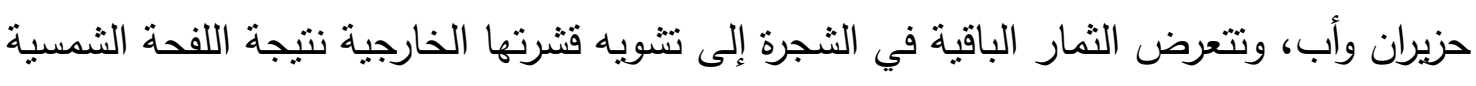
فيضطر المزارع إلى جني المحصول قبل نضجه بشكل جيد وطرحه في الأسواق (كخلال

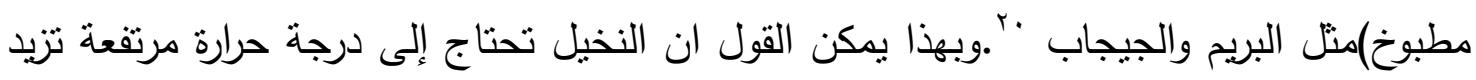


صيفا عن • كُم وكلما ازدادت كان ذلك في صالح الإنتاج ولاسيما في اشهر النضج ،وعلى العكس

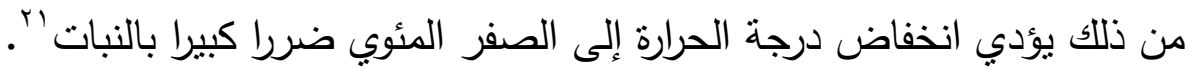

r- الحدود الحرارية الدنيا لزراعة النخيل

يقصد بالحد الأدنى للحرارة بانه درجة النمو الصغرى وهي أدنى درجة من الحرارة التي

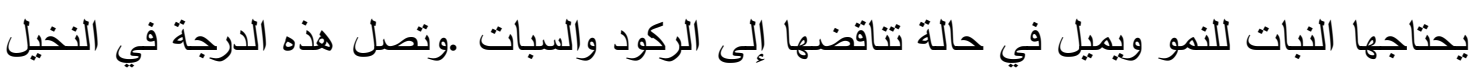
الى-rازٌ ويعد هذا الحد المثالي لزراعتها ويطلق عليها المدى التصنيعي لانتثار النخيل

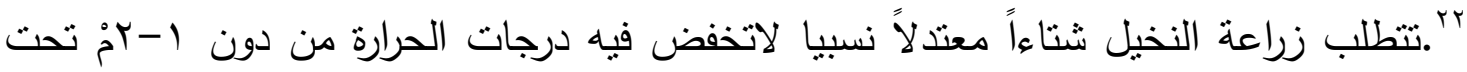

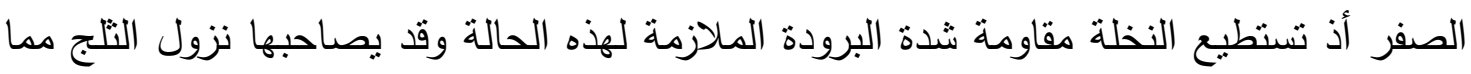

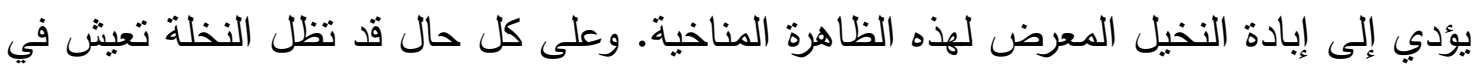

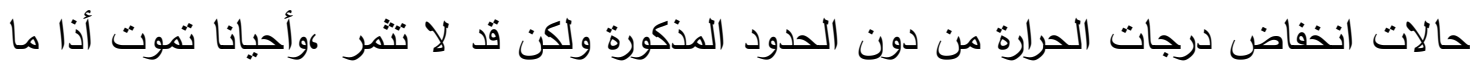

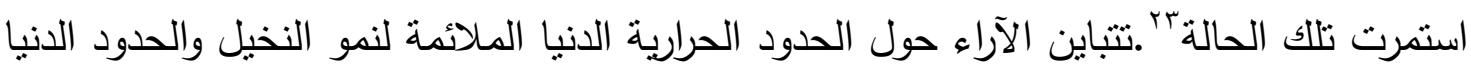

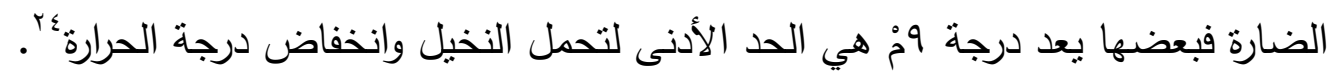

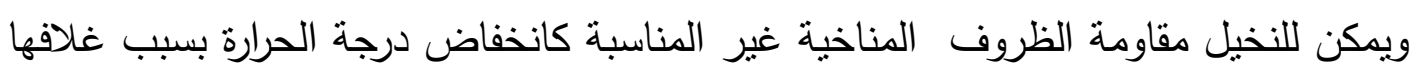
السميك المكون من قواعد الأوراق السعف (الكرب) واليف الذي يحيط بجذع النظلة فيجعلها

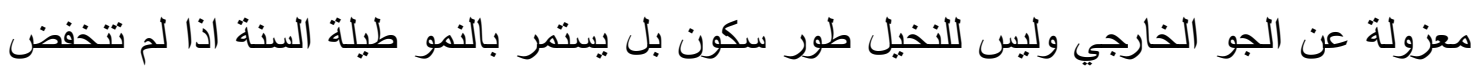

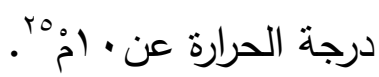

\section{فصل النمو والحرارة المتجمعة} صفر النمو zero of growth وهي الدرجة الني يبدأ عندها المحصول بالنمو بr. بوفي تعريف آخر لفصل النمو point of growth-zero وهي الدرجة التي عندها تبدأ نباتات المنطقة المعتدلة بالنمو في أوائل الربيع ل. والمقصود بفصل النمو بأنه الفترة الزمنية التي ينطلبها المحصول

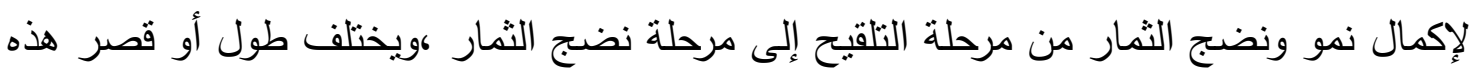

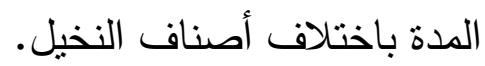




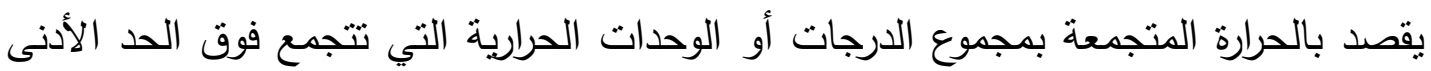

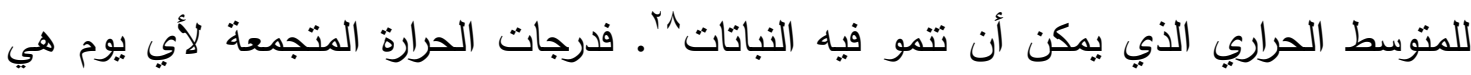

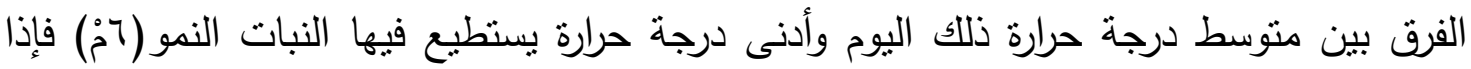

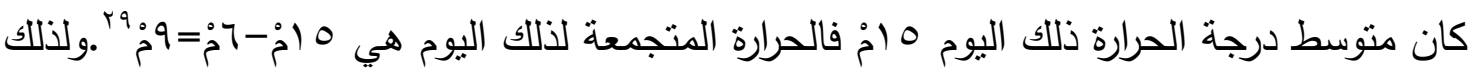

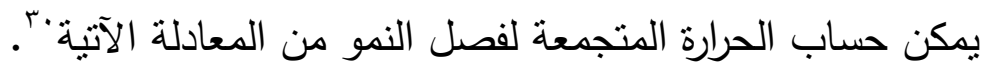
الحرارة المتجمعة(م)=المعدل الحراري الثهري "ح"-الصفر النوعي "ص" *عداد أيام النمو والنضج وعليه فأن فصل النمو المثالي هو الذي يوفر الطاقة الحرارية أو وحدات الحرارة التي يحتاجها

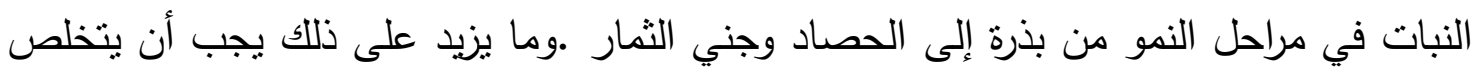

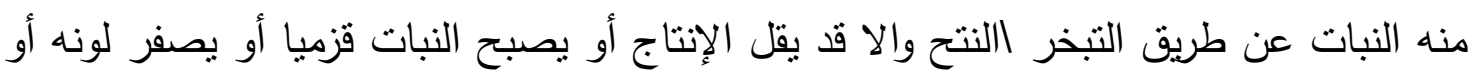

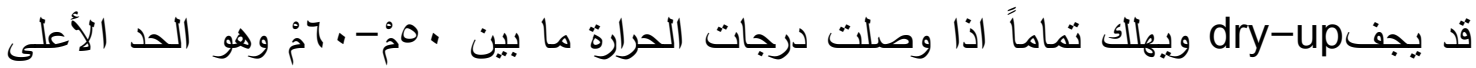
الممكن لعيش النبات وكذللك الحال اذا ما هبطت الوحدات الحرارية دون الصفر ،ققد تؤدي إلى الى

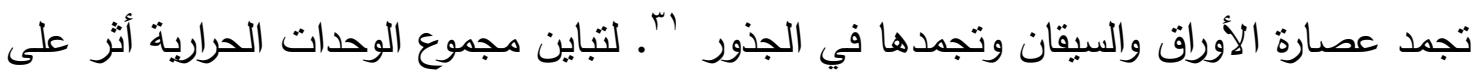

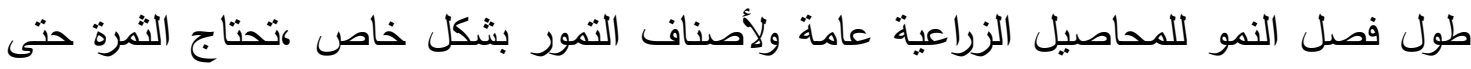

$$
\text { تتضج حوالي م ايوم. }
$$

\section{عناصر مناخ منطقة الدراسة}

تتباين زوايا الإشعاع الثمسي في منطقة الدراسة تبعا لحركة الثمس الظاهرية ، ففي بـ أيلول

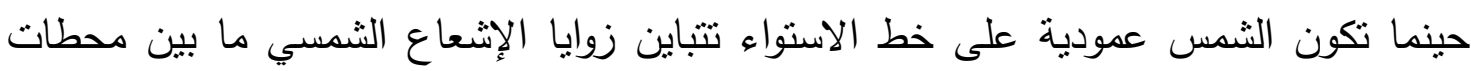

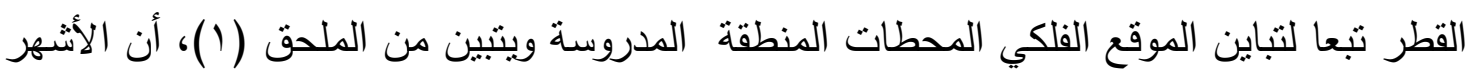

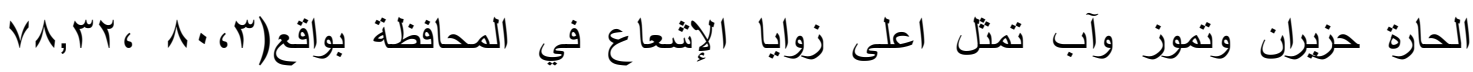

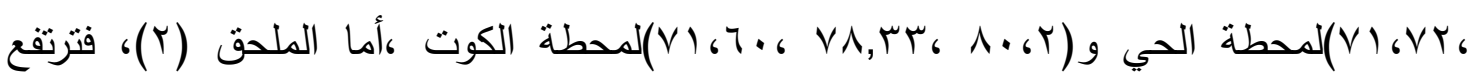

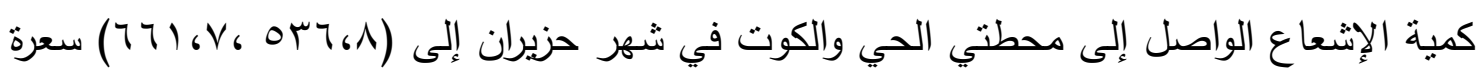
/سم ك/يوم على التوالي. 


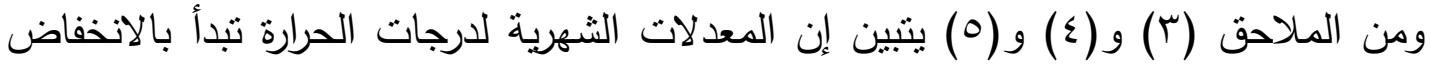

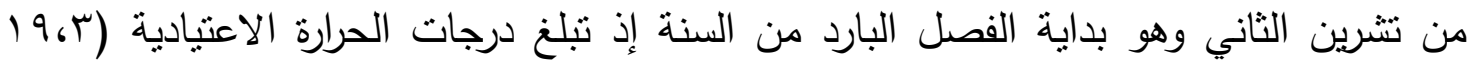

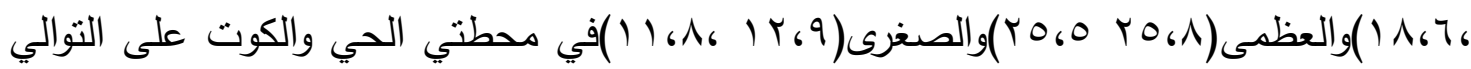
كوتتخف معدلات الحرارة تدريجيا لتصل محطة الحي في شهر شباط (ا،ع امُ لدرجة الحرارة

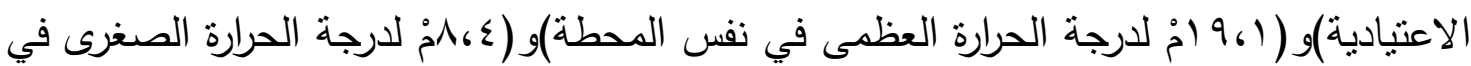

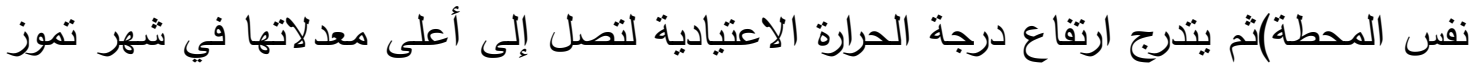

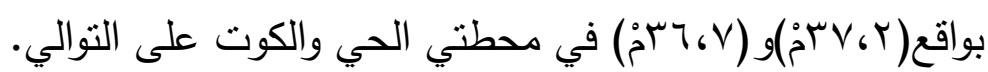
أما الأمطار فتتبع نظام سقوط المطر في العراق نظام أمطار البحر المنتوسط في موسم

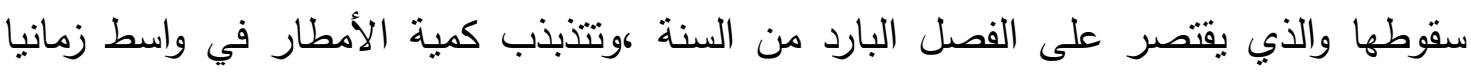
ومكانيا تبعا للعديد من العوامل كطبيعة عدد المنخفضات التي تصل إلى القطر ، وتباين مستوى الارتفاع عن مستوى سطح البحر ،وطبيعة التيار النفاث المندمج وتباين نسبة تأثير كل منهما

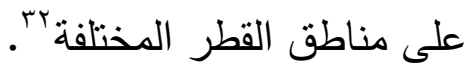
ومن الملحق(7) يتبين ان أعلى كمية أمطار تسقط في شهر كانون الثاني بكمية

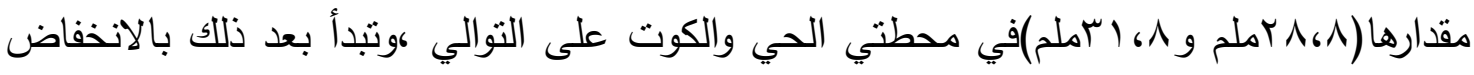
تدريجيا لتصل إلى (1،عملم و r، ملم)في شهر مايس في محطتي الحي والكوت على التوالي

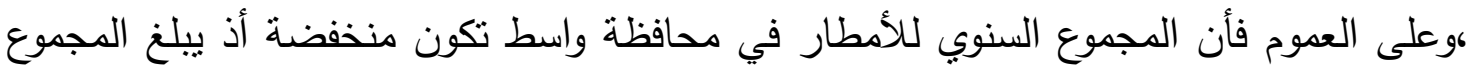
السنوي للأمطار في محطة الحي (1، گ (ملم)بينما تتخفض إلى أكثر من ذلك في محطة الكوت

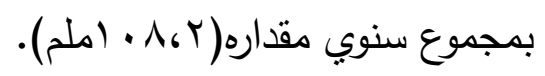

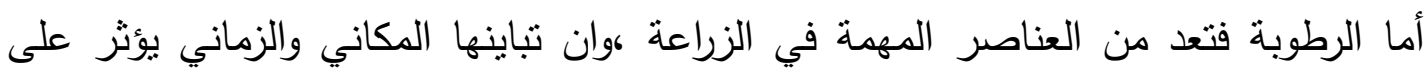
مختلف الفعاليات والأنشطة الحيوية للنبات ،وتكون بينها وبين التبخر/النتح علاقة عكسية فزيادة الرطوبة النسبية في الجو تعني قلة التبخر/النتح ومن ثم قلة حاجات النبات للري أو المياه والعكس بالعكس ،وينتين من الملحق (V)ان أعلى رطوبة نسبية نم قياسها كانت في كانون الثاني 


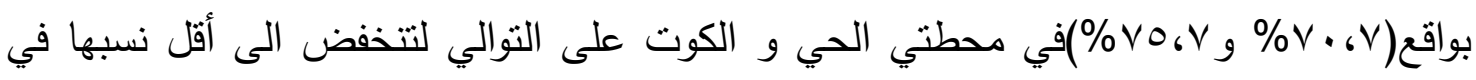

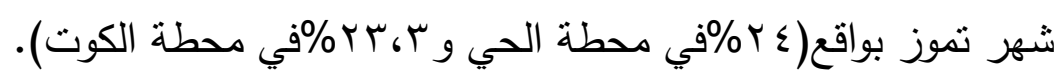

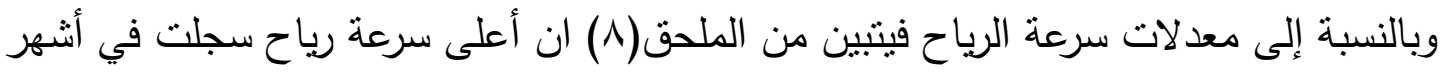

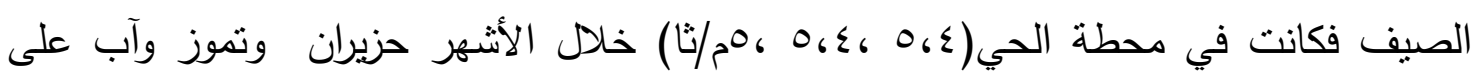
• التوالي

ومن الملحق (9)ينتين ارتفاع معدلات التبخر في المحطنين فتكون على أعلاها في أنشهر

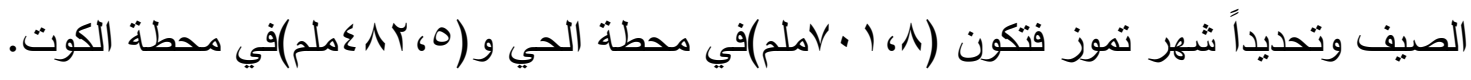

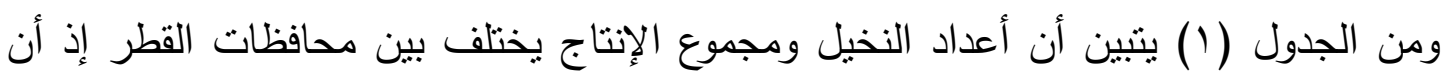

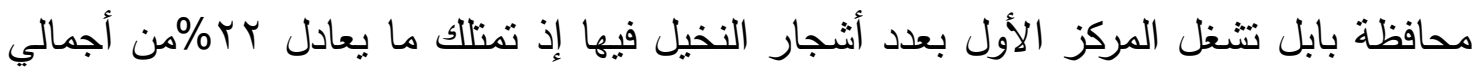

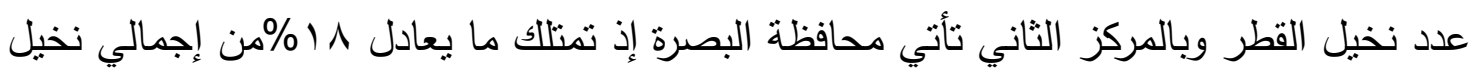

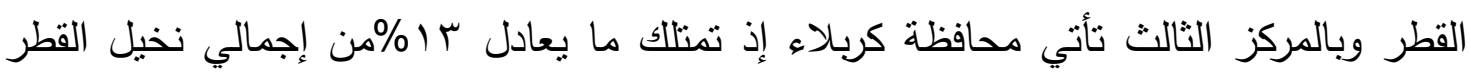

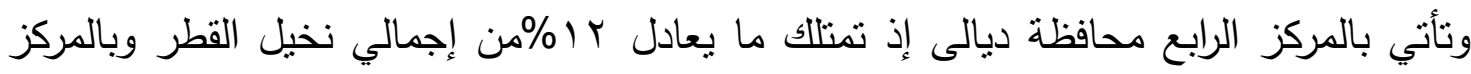

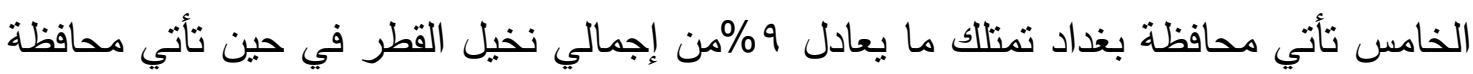

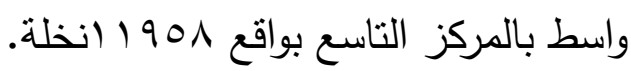

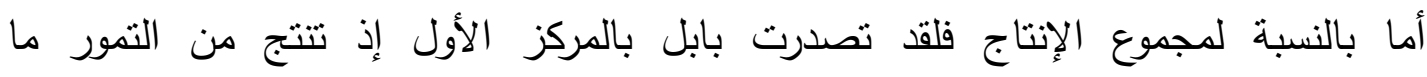

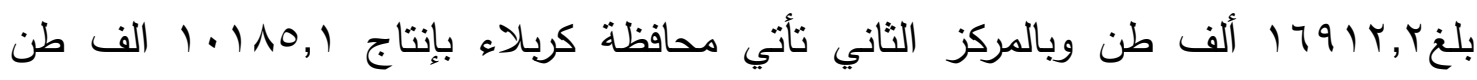

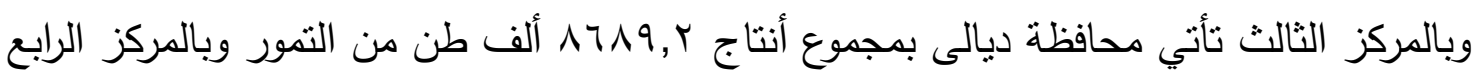

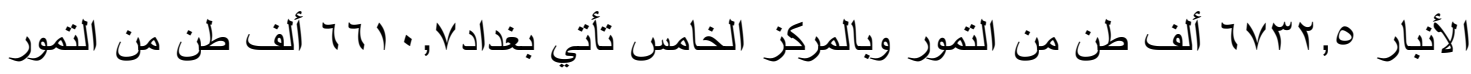

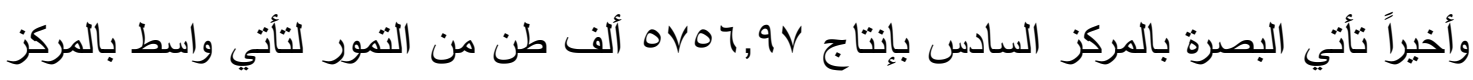

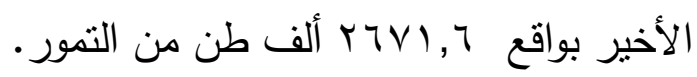

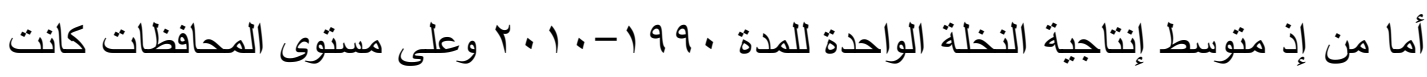

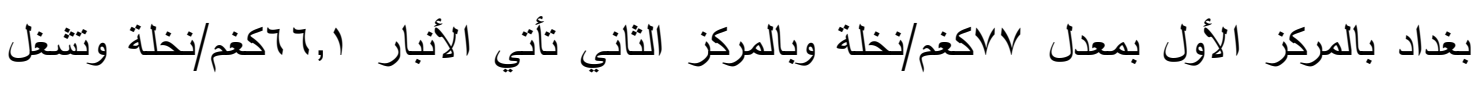

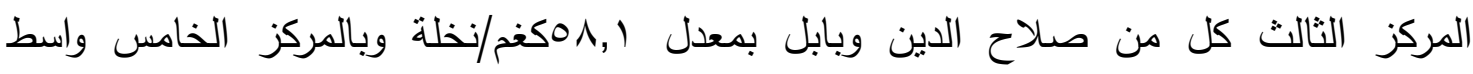


وكربلاءr ,00 ،00ركغ/نخلة في حين نجد أقل متوسط إنتاجية للنخلة الواحدة في محافظة البصرة

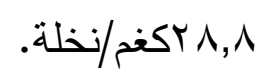

جدول( (1)المعدلات العامة لعدد أثنجار النخيل ومجموع الإنتاج ومنوسط الإنتاجية على مستوى

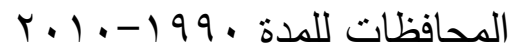

\begin{tabular}{|c|c|c|c|}
\hline متوسط الإنتاجية(كغم) & مجموع الإنتاج طن & عدد الأشجار & المحافظة \\
\hline $7, r$ & $r Y I \leqslant, V$ & $V V \cdot q, \varepsilon$ & صلاح الدين \\
\hline or, \& & $\wedge \uparrow \wedge q, r$ & $r \Delta V \leqslant 7, Y$ & 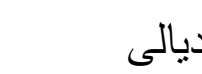 \\
\hline V V & $771 \cdot, V$ & ro.9 & 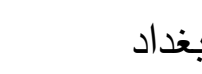 \\
\hline 74,1 & TVMY,O & $1 \leq \vee q r$ & الأنبار \\
\hline 7. & $1791 r, r$ & $990 Y \leqslant$ & بابل بابل \\
\hline 00 & $1 \cdot 110,1$ & $\{1 \times 10$ & كربلاء \\
\hline$r q, 7$ & $r \leqslant \mid \leqslant, \wedge T$ & 14991 & النجف \\
\hline $0 ., \mathrm{V}$ & $r T \leq \varepsilon, V$ & $17 V \leqslant 0, \varepsilon$ & القادسية \\
\hline $0 \wedge, 1$ & $|\Lambda| \leq \cdot, 0$ & $r \lambda \leqslant r$ & المثىى \\
\hline$r 0,7$ & roo9,19 & $1 \leq \Lambda \cdot \varepsilon$ & ت ذي قار \\
\hline $00, r$ & YTVו,T & 11901 & واسط \\
\hline 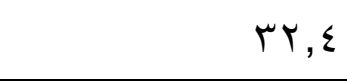 & $\vee r \Lambda, T$ & $\varepsilon \cdot \varepsilon$ & ميسان \\
\hline$r \wedge, \wedge$ & $0 V 07,9 \vee$ & $r V \leqslant \wedge \vee$ & البصرة \\
\hline
\end{tabular}

المصدر:-وزارة الزراعة ،الهيئة العامة لزراعة المنطقة الجنوبية ،شعبة الدراسات ،بيانات غير منشورة 
التحليل الإحصائي

هنالك جملة من العوامل المختلفة التي نشترك بالتأثير على أنتاج التمور في واسط ، فمنها ما هو ذو تأثثر مباشر كالعوامل الطبيعية المتعلقة بكمية المياه ونوعية التربة والأمراض والآفات وعناصر المناخ المختلفة ،ومنها ما هو ذو تأثير غير مباشر كالعوامل البشرية ومدى العناية المبذولة في خدمة التربة والتسميد وخدمة قمة النخلة(طريقة التلقيح)وكذلك طريقة جني الثمار لمحصول التمور، إذ تؤدي هذه العوامل مجتمعة إلى تباين متوسط إنتاجية الثجرة الواحدة من التمور •

تم الاعتماد في هذه الدراسة على منوسط إنتاجية الثجرة الواحدة من التمور كدالة لمعرفة مدى تأثثر عناصر المناخ المختلفة على تباين منوسط الإنتاجية، ومن ثم بيان أي العناصر المناخية أكثر تأثثرا على إنتاج التمور في محافظة واسط، ولأجل التوصل إلى هذا الهدف تم الافتراض على ان بقية العوامل الطبيعية والبشرية الأخرى هي الثوابت وذلك لعزل تأثيرها على متوسط إنتاجية التمور .كما طبقت بعض الطرق التحليل الإحصائي من خلال الاستعانة ببرنامج spss وبرنامج minitab لأجراء التحليلات الإحصائية كإحدى الطرائق النظرية لتفسير وجود علاقة إحصائية بين المتغيرات ،وقد تكون هذه العلاقة مقاربة لما هو موجود في الواقع أو بعيدة عنه، وهذا يعتمد على دقة البيانات المدخلة، كما ونوعا وذلك من خلال استخدام بعض الطرائق الإحصائية في التحليل والتي تشمل:- (تحليل الانحدار الخطي

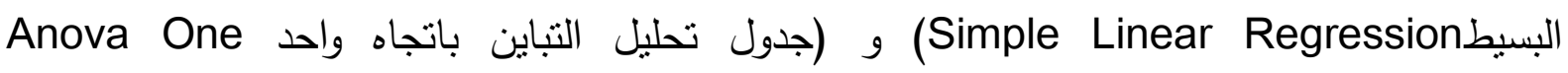
(Way) (تحليل اختبار اقل الفروقات معنوية LSD)،ويعكس لنا معامل الانحدار البسيط عند تطبيقه بين كل عنصر مناخي ومتوسط إنتاجية الثجرة الواحدة أو النخلة الواحدة مدى قوة علاقة الارتباط بين كل واحد منهم. فتبلغ قيمة معامل الارتباط R للنخيل بين درجات الحرارة ومنوسط إنتاجية النخلةrا, · وهي علاقة قوية وتأتي بالدرجة الأولى من بين العناصر المناخية بتأثيرها على متوسط إنتاجية النخلة، ومن بعدها تأتي وبالدرجة الثانية كمية الإثعاع الثمسي الواصل ومتوسط الإنتاجية إذ تبلغ 77, • وهي علاقة قوية أيضا، وبالدرجة الثالثة معدل التبخر/النتح الحقيقي ؟7,، وتتعدم الأمطار خلال فصل نمو ثمار النخيل وعلية تكون درجات الحرارة وكمية الإشعاع الثمسي الواصل ومعدل التبخر/النتح الحقيقي هي من 
العناصر المناخية ذات التأثير المهم والكبير على متوسط إنتاجية النخلة ومن ثم على أنتاج التمور في محافظة واسط.

لقد تم تحويل البيانات المناخية إلى درجتها المعيارية، ومن ثم تقسيمها أو تصنيفها إلى فئات تشمل كل فئة مناطق معينة وبحسب درجتها المعيارية ،ومن ثم موازنتها مع متوسط إنتاجية النخلة الواحدة فيها جدول تحليل التباين باتجاه واحدAnova One Way.لمعرفة مدى وجود الفروق الإحصائية فيها ومستوى دلالتها ،كما تم تقسيم واسط إلى أقاليم أو مناطق حرارية بالاعتماد على الدرجة المعيارية وكما

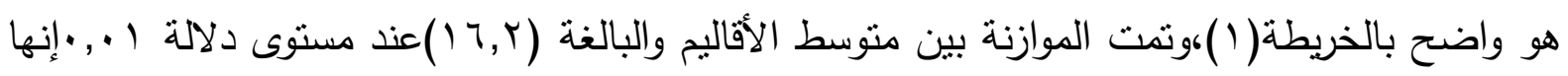

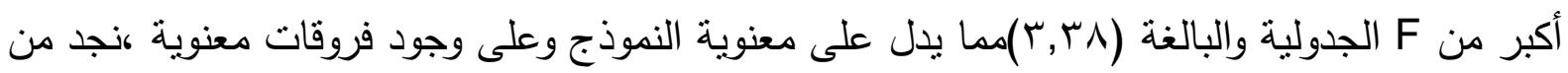
الجدول (Y)) هنإن فروق ذات دلالة إحصائية كبيرة بين الفئات (-r+هفر) (إذ بلغت قيمة المتوسط

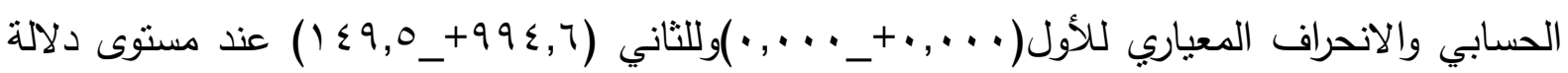
أقل من ا .......،كما أن هناك فروقا ذات دلالة إحصائية كبيرة بين كل من (-(،-صفر)بمتوسط

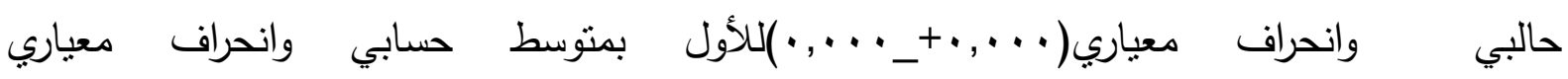

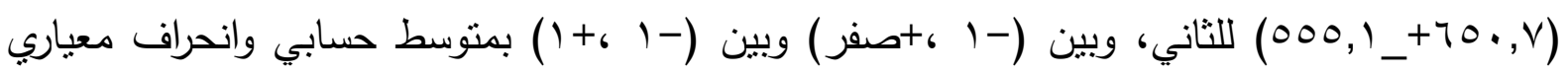

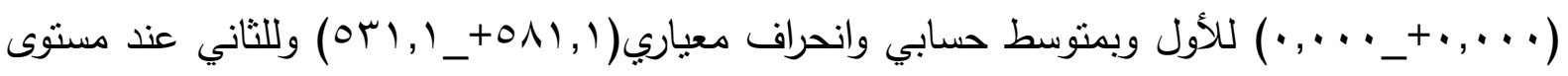

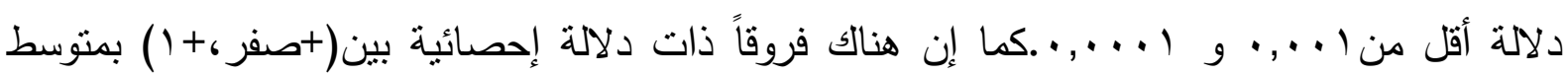

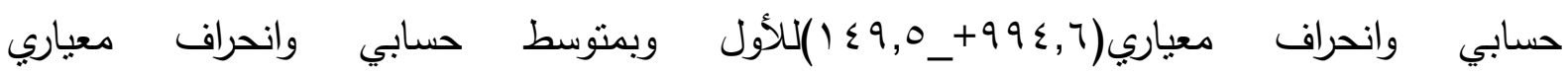

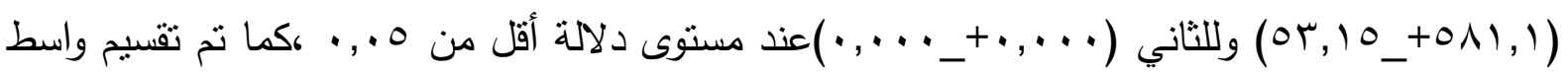
إلى أقاليم ككمية الإشعاع الثمسي الواصل أو المستلم بالاعتماد الدرجة المعيارية له وكما في الخربطة(ץ)حيث تشير قيمة F الجدولية والبالغة(ی,r,r) مما يدل على معنوية النموذج وعلى وجود فروقات معنوية ومن خلا الموازنة بين متوسط الأقاليم المناخية لمعرفة مستوى دلالة الفروق بينها وجدنا إن هناك فروق ذات دلالة إحصائية كبيرة بين (- او +صفر)بمتوسط حسابي وانحراف 
خريطة ( ) الأقاليم الحرارية لزراعة أثجار النخيل على وفق درجاتها المعيارية في محافظة واسط

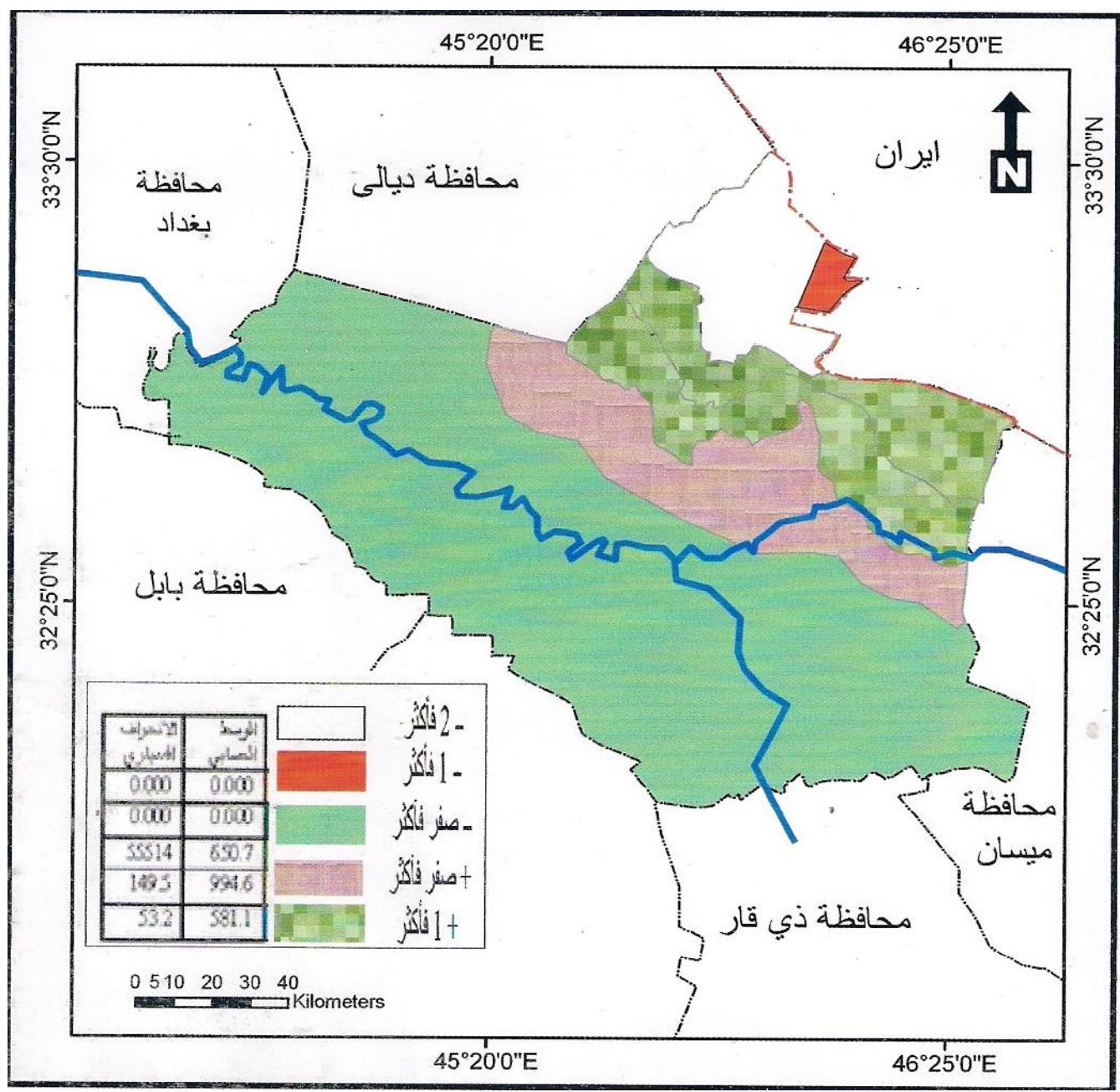

المصدر :- من عمل الباحثة اعتماداً على جدول (Y) 
جدول (Y)متوسط إنتاجية النظلة على وفق درجاتها المعيارية للأقاليم الحرارة

\begin{tabular}{|c|c|}
\hline الوسط حسابي +_ الانحراف معياري & الفئات \\
\hline$\cdot, \cdots++, \cdots$ & أكثر من-r \\
\hline$\cdot, \cdots++, \ldots$ & أكثر من-1 \\
\hline $000,1+70 \cdot, V$ & أكثر من -صفر \\
\hline $1 \leq 9,0_{-}+99 \leq, 7$ & أكثر من +صفر \\
\hline $0 r, 10_{+}+011,1$ & أكثر من +1 \\
\hline mo, IV & LSD \\
\hline
\end{tabular}

المصدر :- من عمل الباحثة اعتماداً على جدول ( () والملحق(r)

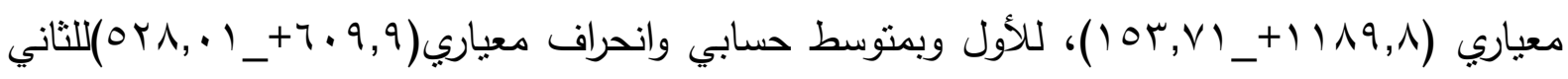

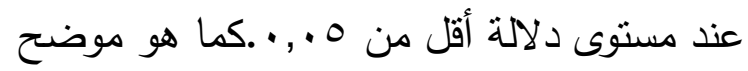


خريطة (r)|قاليم زراعة أثجار النخيل على وفق الدرجة المعيارية لكمية الاشعاع الثمسي الواصل

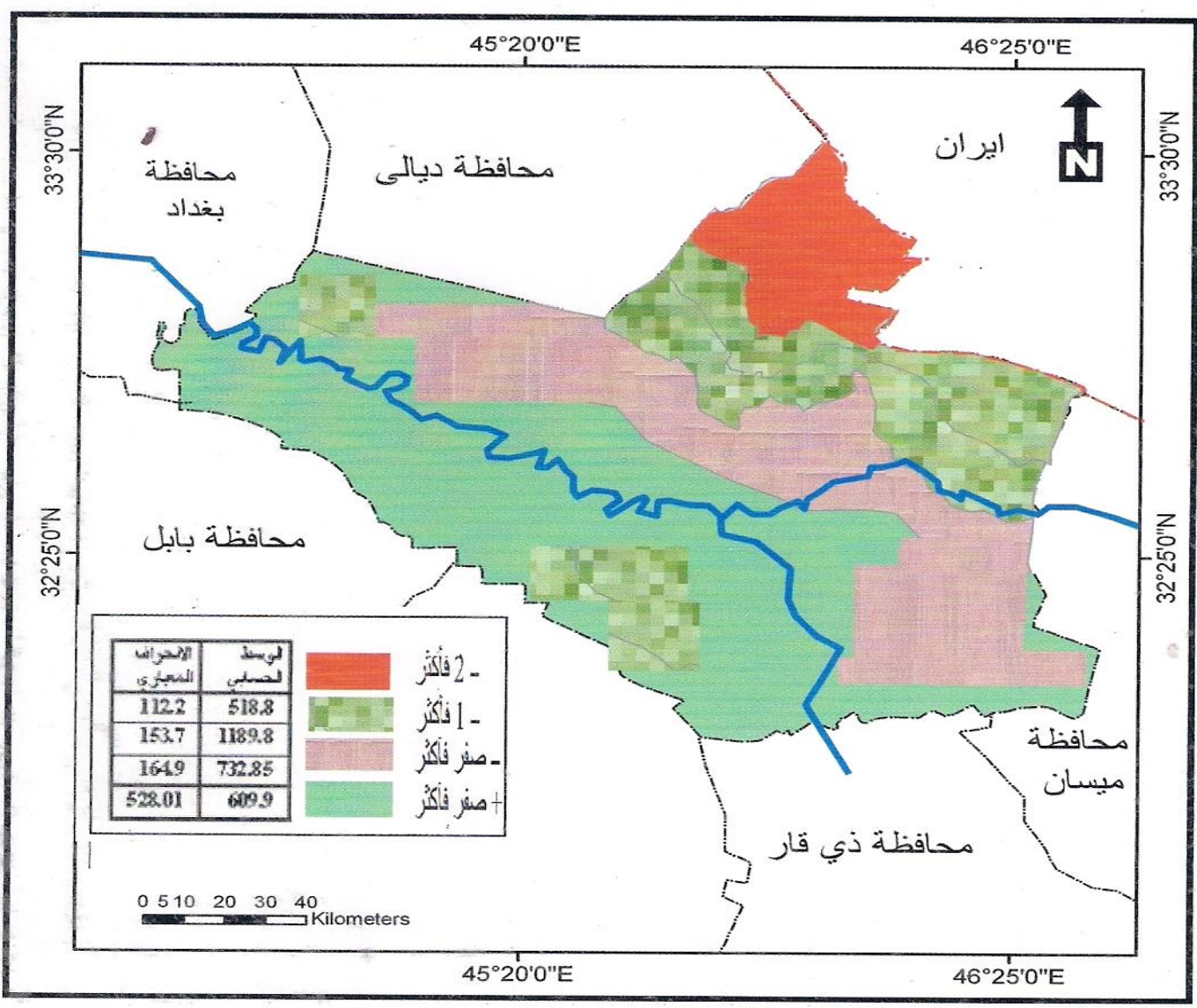

المصدر :- من عمل الباحثة اعتمادا على جدول(r) والملحق(؟) بالجدول (r) كما إن هناك فروقاً دالة إحصائيا بين (- (و -r) بمتوسط حسابي جدول (r) متوسط إنتاجية النظلة على وفق درجتها المعيارية لأقاليم كمية الإتعاع الثمسي الواصل

\begin{tabular}{|c|c|}
\hline الوسط حسابي +_ الانحراف معياري & الفئات \\
\hline$\cdot, \cdots++1 . / 011$ & رُ من -r \\
\hline
\end{tabular}




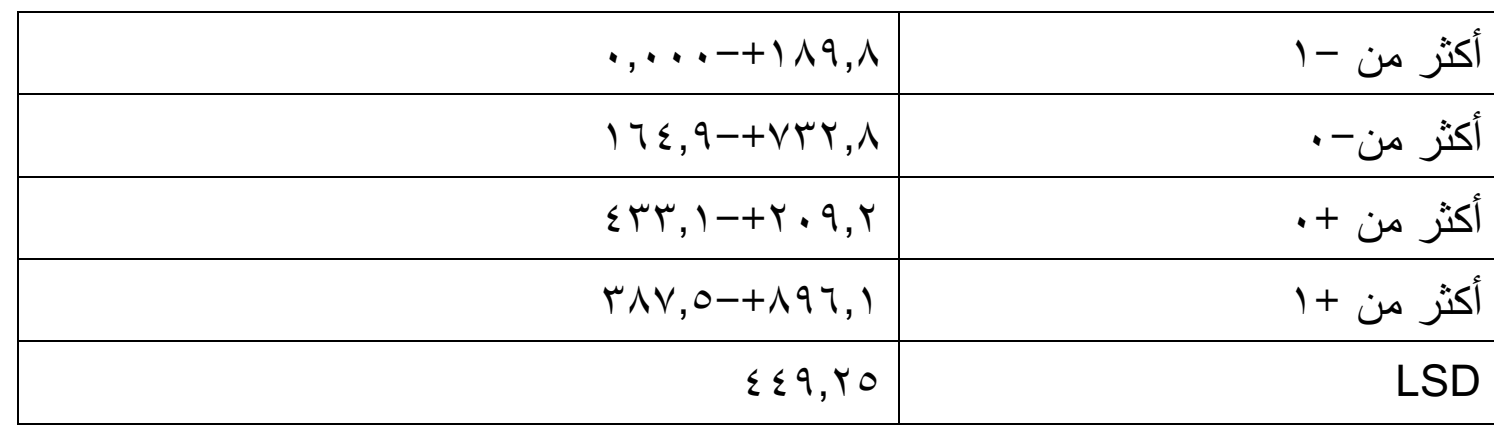

المصدر :- من عمل الباحثة اعتمادا على جدول(Y)والملحق(Y)

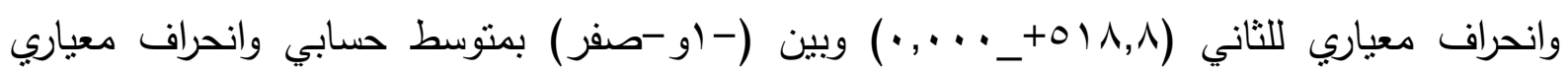

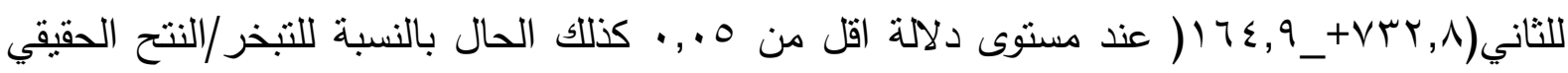

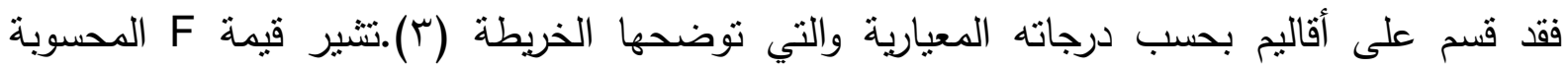

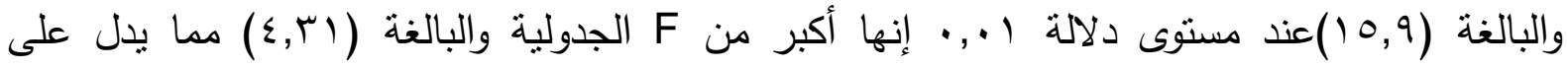

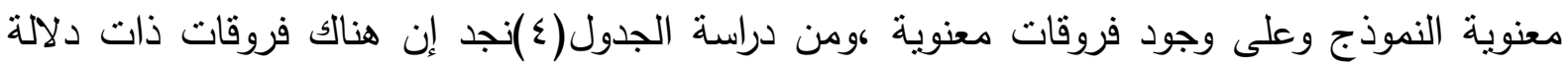

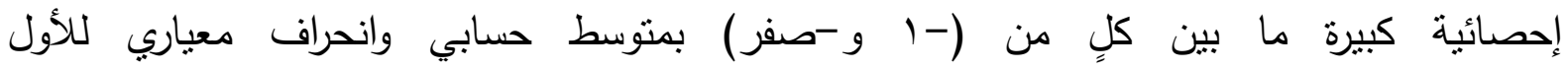

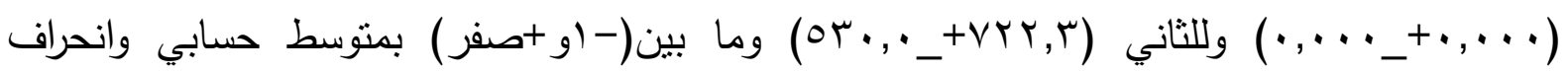

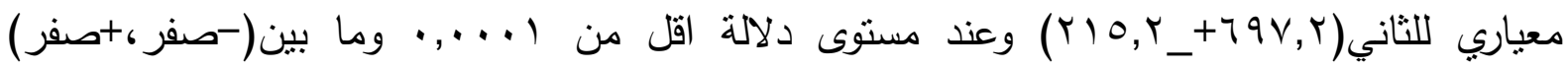

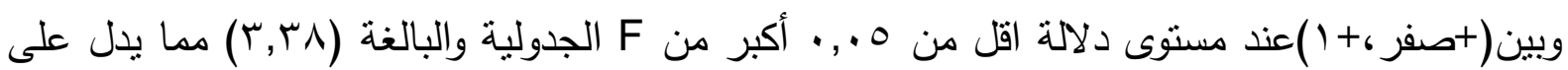
معنوية النموذج وعلى وجود فروقات معنوية .

جدول (؟) متوسط إتتاجية النظلة على وفق درجتها المعيارية لأقاليم كمية التبخر/النتح الحقيقي مع متوسط الإنتاجية للنظة الواحدة

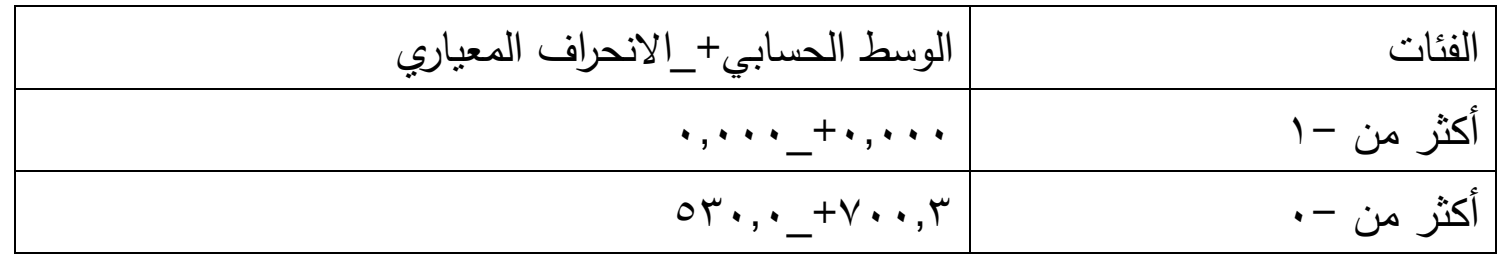




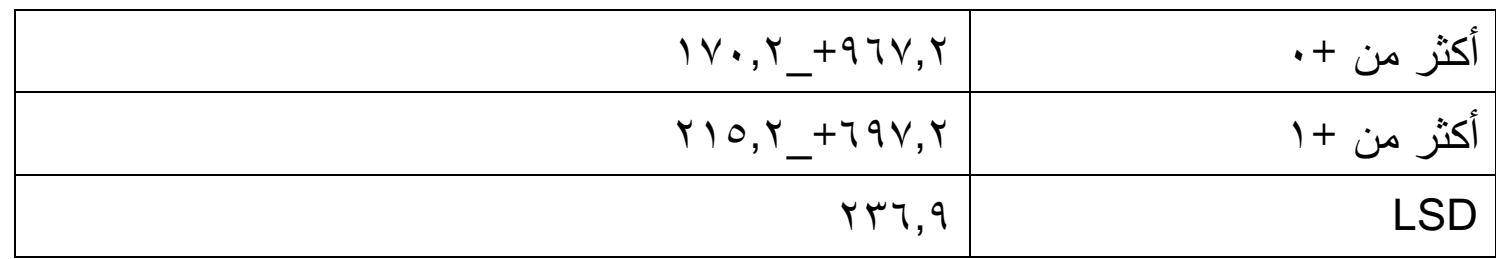

المصدر :- من عمل الباحثة اعتمادا على جدول(ب)والملحق()

خريطة (ب)أقاليم زراعة أثجار النخيل على وفق درجاتها المعيارية لكمية التبخر/النتح الحقيقي

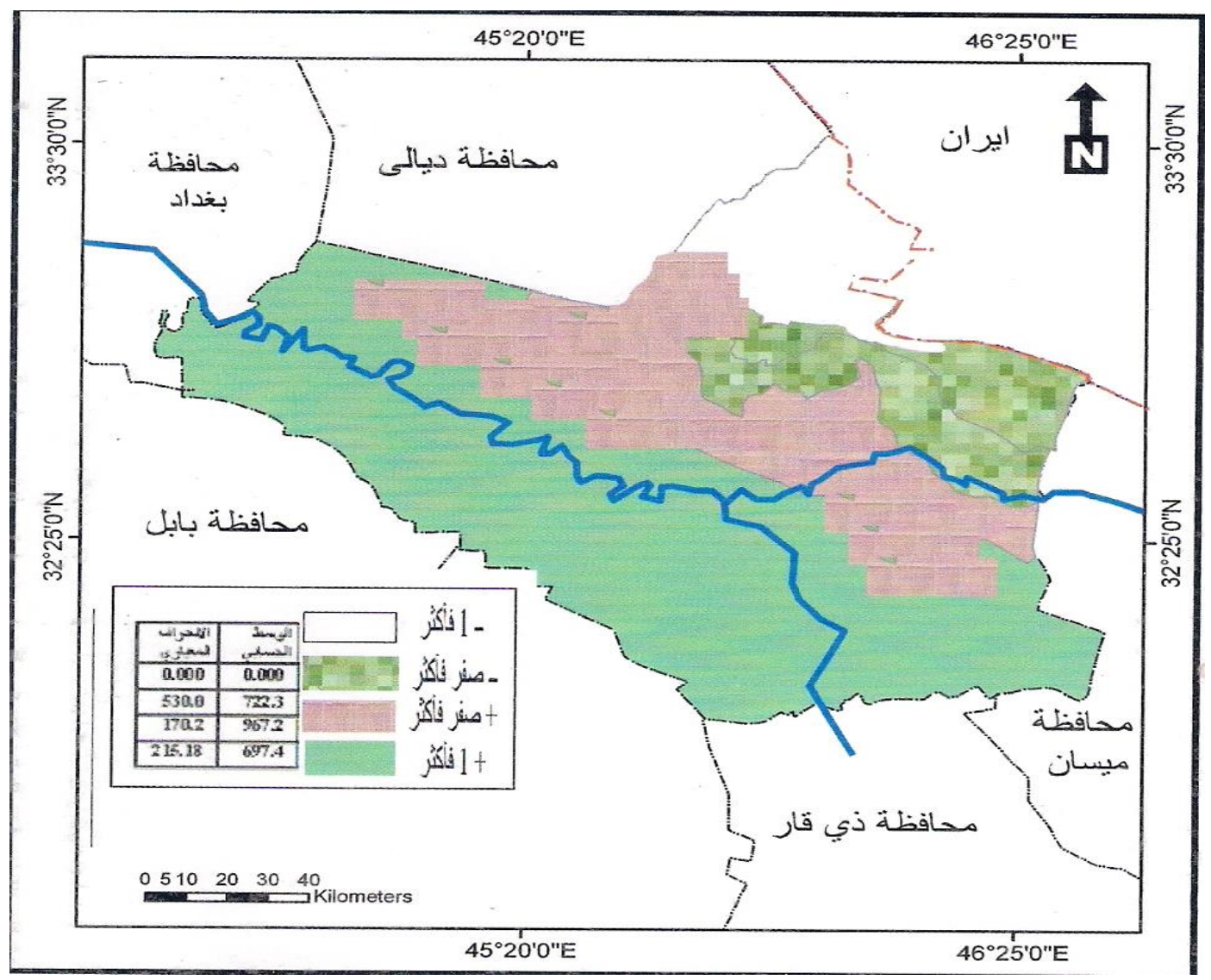

المصدر :- من عمل الباحثة اعتمادا على جدول(؟)

الاستنتاجات

\section{रिद}


ا . يزداد مجموع الوحدات الحرارية المتجمعة خلال فصل نمو النخيل تدريجيا ابتداءً من شهر نيسان

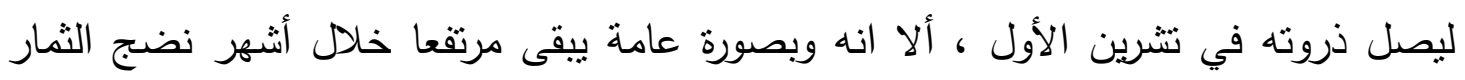

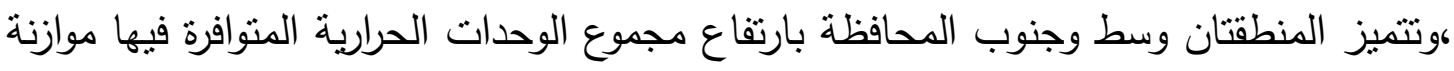

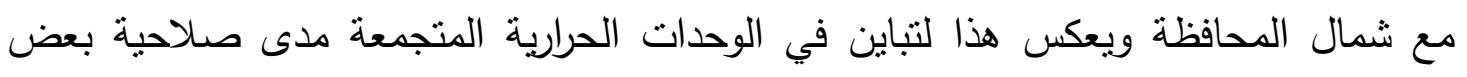

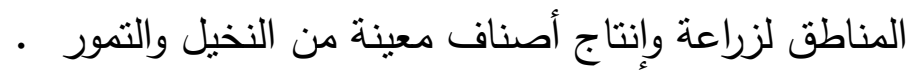
r. تذبذبت أعداد أثجار النخيل ومجموع الإنتاج ومتوسط الإنتاجية مكانيا ما بين مناطق الدحافظة الناف

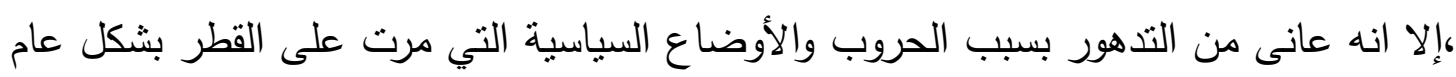

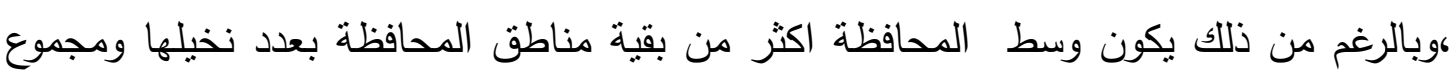
الإنتاج ومتوسط إنتاجية النخلة فيها. r. أثنتت التحليلات الإحصائية مدى قوة العلاقة بين العناصر المناخية ومتوسط إنتاجية أثنجار

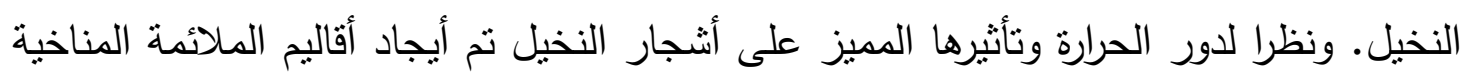

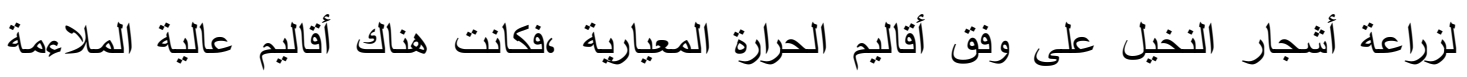

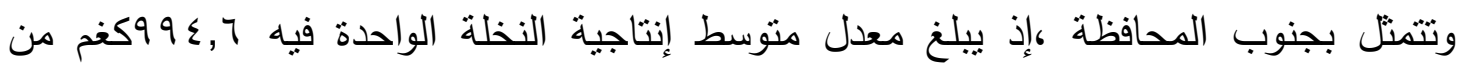

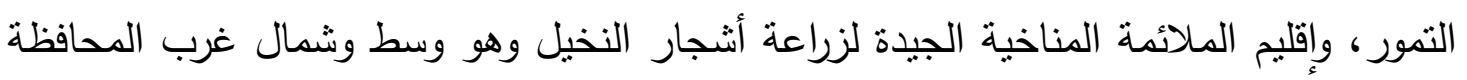

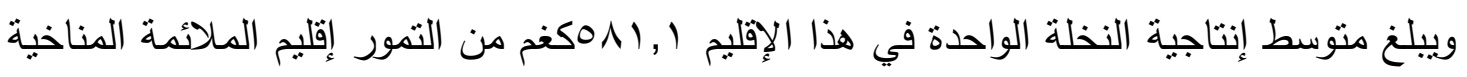

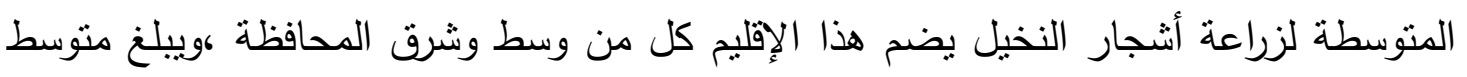

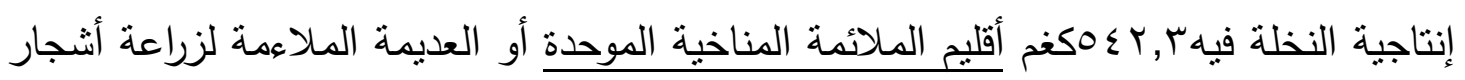
النخيل يشمل هذا الإقليم اقصى شمال شرق المحافظة قرب الجبال الإيرانية ،إذ تكون النخيل فيها

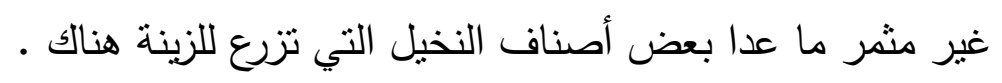
التوصيات

ا. توصي الباحثة بزيادة زراعة أشجار النخيل بأنواعه المتعددة وإدخال أصناف جديدة نظرا

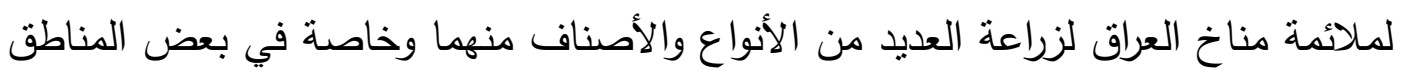

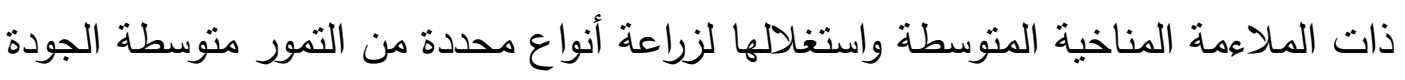


والعمل على تطوير وتتمية زراعة أجود أنواع التمور المشهورة عالميا وتجاريا في الملائمة

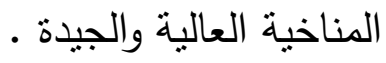

r. تطوير الصناعات التي تدخل بها التمور كمادة رئيسية أو ثانوية إذ يُعد عاملاً مشجعاً للفلاحين وأصحاب الأراضي على زيادة زراعتها.

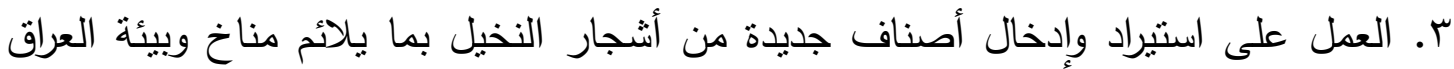

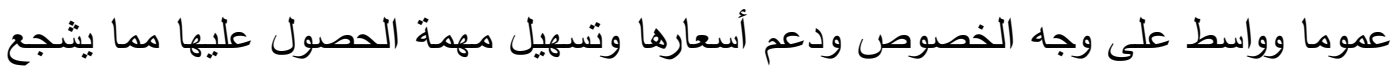
الفلاحين والمستثمرين على زراعة أراضيهم واستثمارها لهذا المحصول.

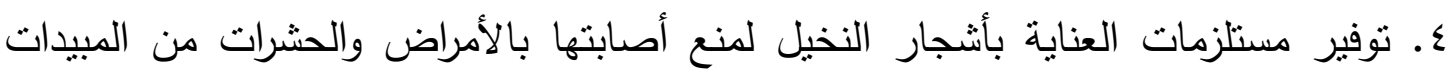

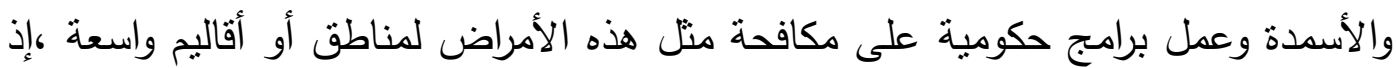
ان هنالك بعض المناطق تعاني من تدهور في أنتاجها من التمور. 


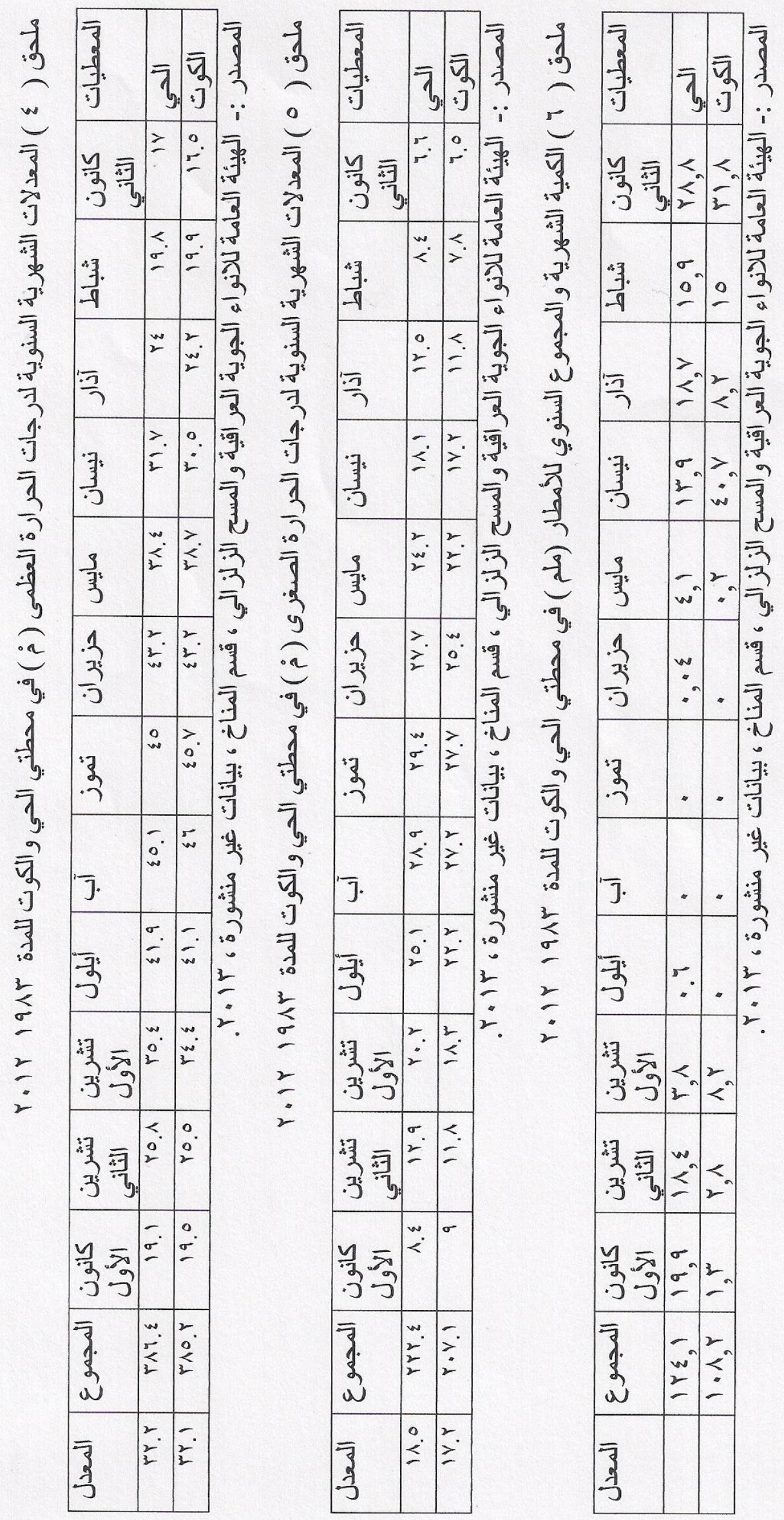




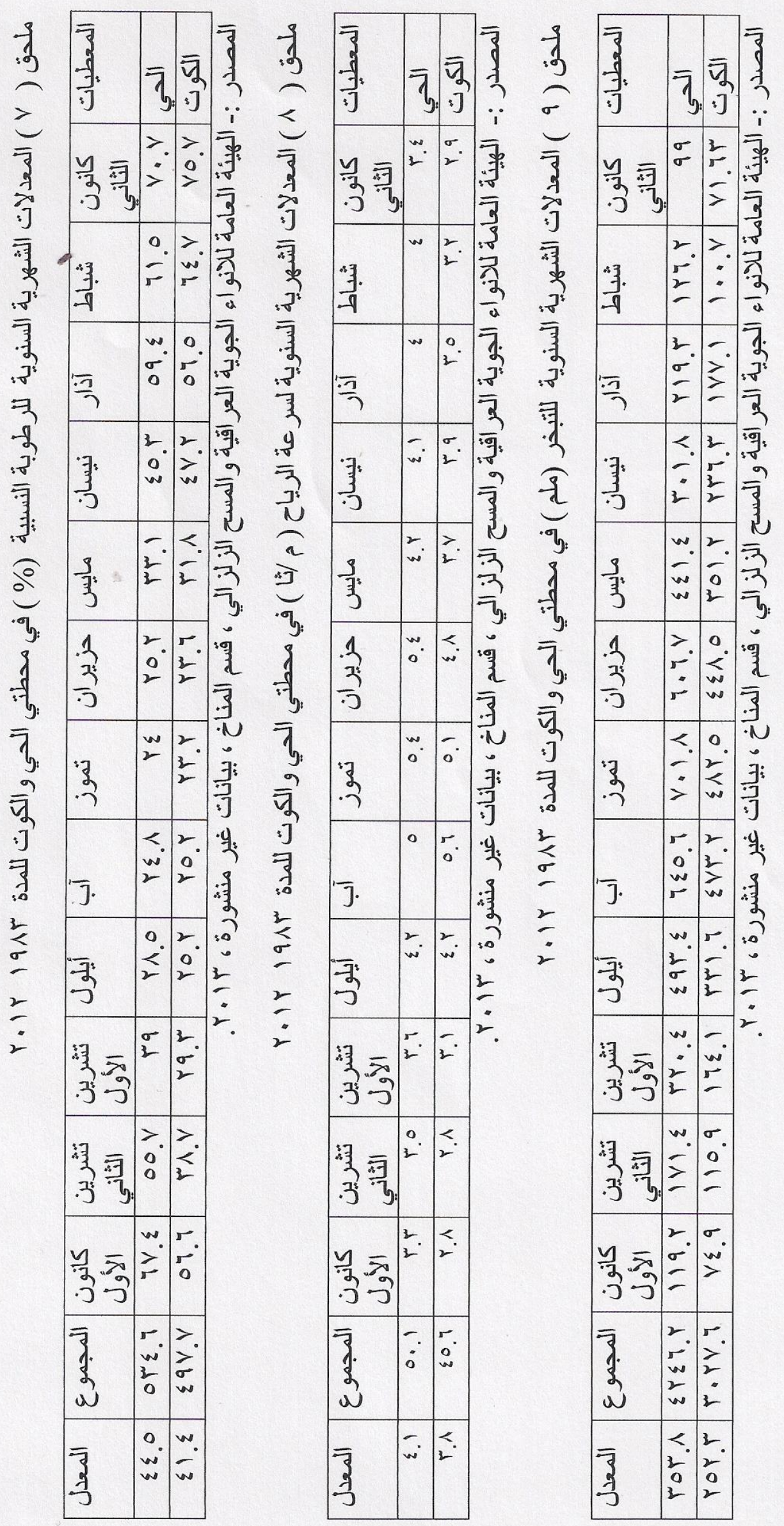


A.C. Hildreth, J.R. Mage ness and Johan Michelle effects of climatic factors on Growing Plants climate and man, year book of Agriculture,1941.p

- D.R.M Smoky and A. M. Hubert ,economic gropes vol.11,newyork.1950.p:36. ` Joseph. Evan Riper, Mans physical world, MC Grow Hill Book, New York. 1971.P:48. - ${ }^{r}$ ؛ - - رياض عبد اللطيف ، الماء في حياة النبات ،وزارة التعليم العالي والبحث العلمي، جامعة الموصل ،الموصل

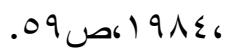

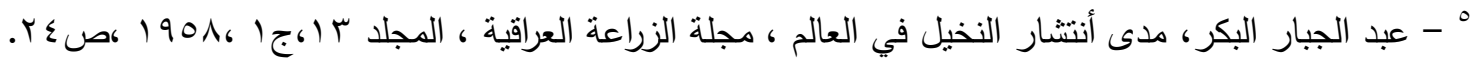

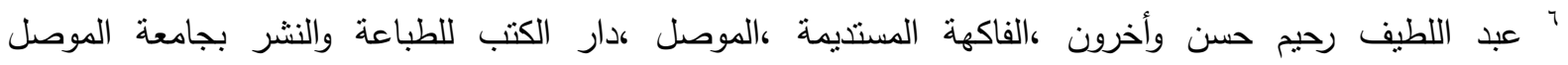
.1.r. (199.6

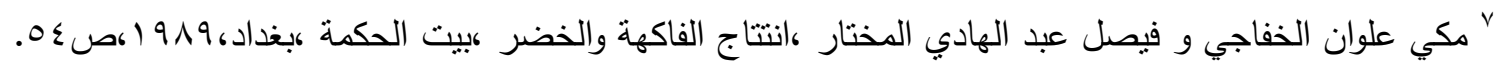

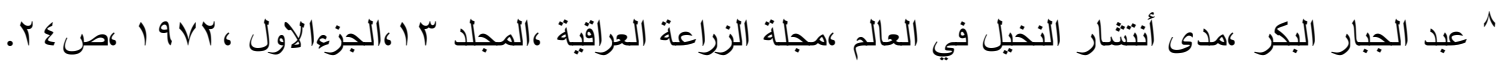

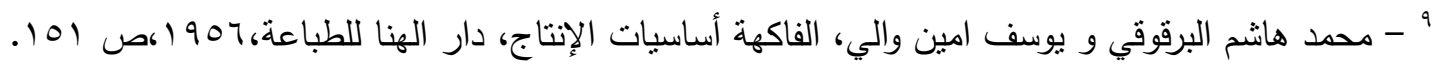

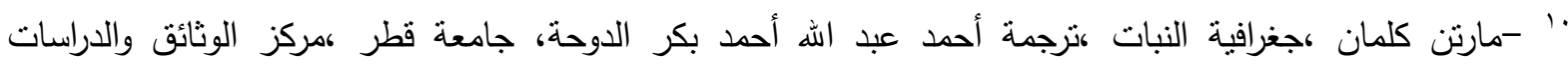

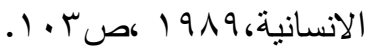

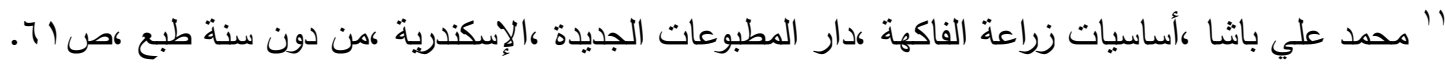
rا "ا قيس جميل عبد المجيد وعلي عبيد الحجيري، النخيل والتمور، وزارة التعليم العالي والبحث العلمي ،هيئة المعاهد الفنية

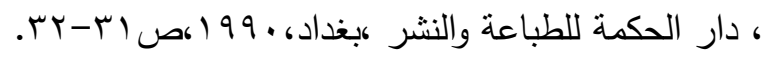
؛' علي حسين الثلش وعبد علي الخفاف، الجغرافية الحياتية، وزارة التعليم العالي والبحث العلمي، مطبعة جامعة

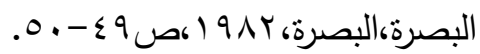

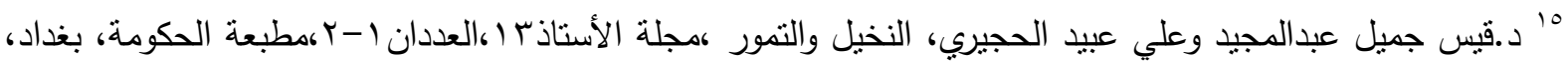

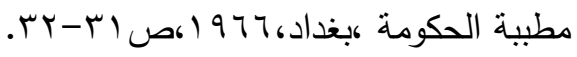

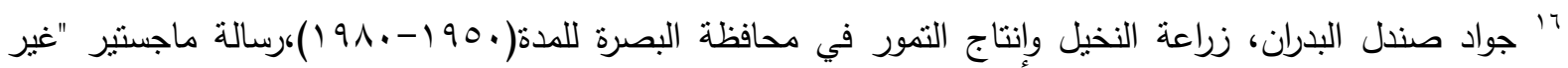

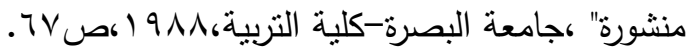




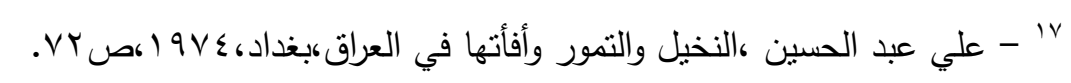

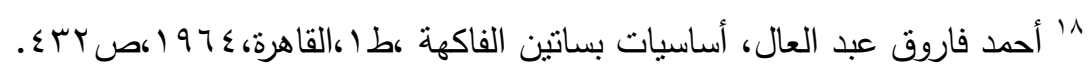

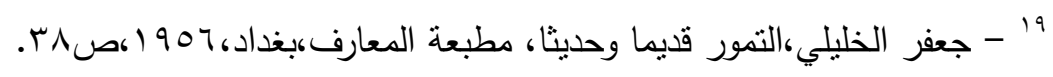

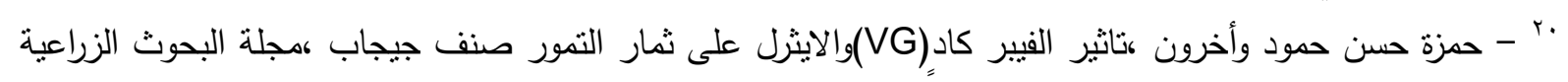

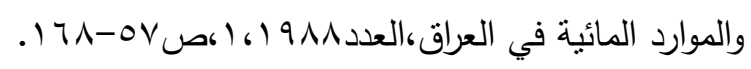

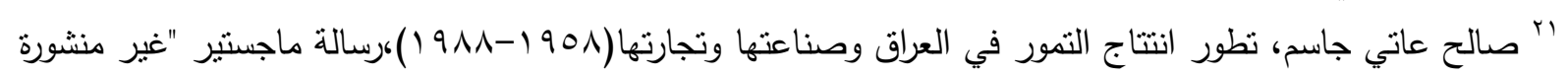

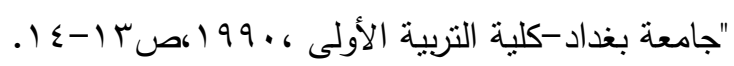

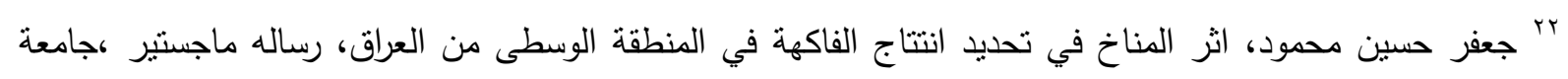

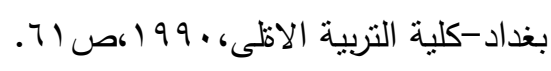

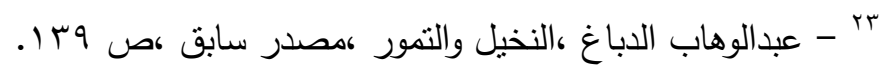

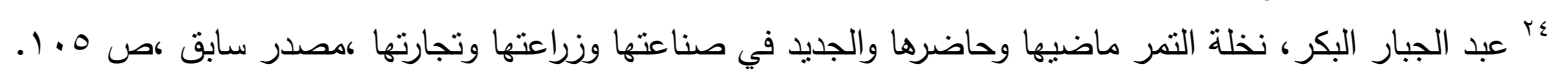

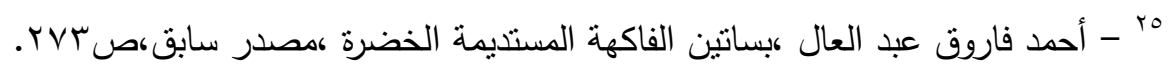
بr علي حسين الثنلش ،أثز الحرارة المتجمعة على نمو ونضج المحاصيل الزراعية في العراق، الجمعية الجغرافية الكويتية،

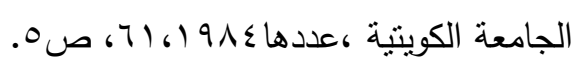
AV

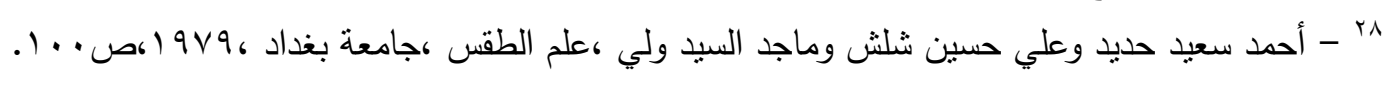

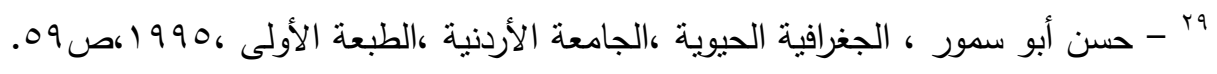

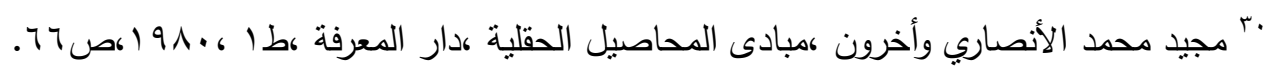

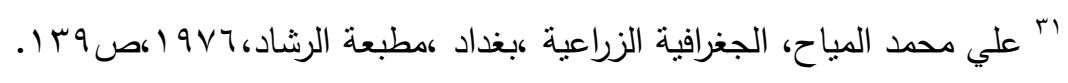

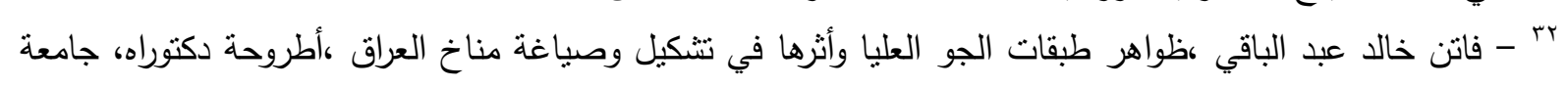

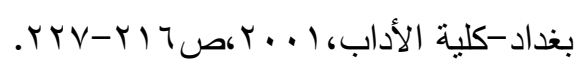




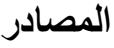

1- أحمد فاروق عبد العال ،أساسيات بساتين الفاكهة ،ط (،القاهرة ،ـ 97 ا. ץ- أحمد فاروق عبد العال ،بساتين الفاكهة المستديمة الخضرة ،دار المعارف ،القاهرة ،طب ،بدون تاريخ.

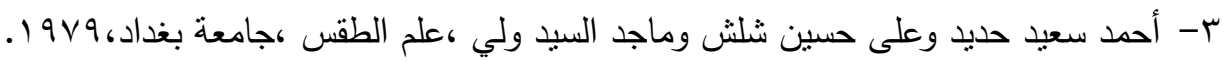

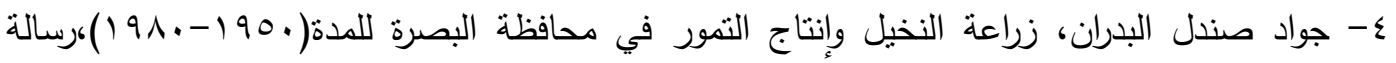
ماجستير" غير منشورة" ،جامعة البصرة-كلية التربية،و1911. 0- جعفر الخليلي، التمور قديما وحديثا ،مطبعة المعارف،بغداد، 1907. 1- جعفر حسين محمود، أثر المناخ في تحديد إنتاج الفاكهة في المنطقة الوسطى من العراق ،رسالة ماجستير ،جامعة بغداد-كلية التربية الأولى، ـ 199 .

V حسن أبو سمور ،الجغرافية الحيوية، الجامعة الأردنية، الطبعة الأولى، 1990 . 1- حمزة حسن حمود وأخرون ،تأثير الفيبركاد(VG) اإلا يثزل على ثمار التمور صنف جيجاب ،مجلة

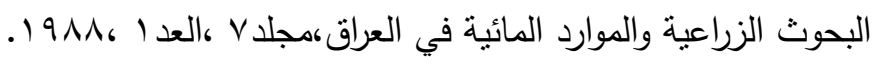

9- مارتن كلمان ،جغرافية النبات ،ترجمة أحمد عبد الهه بكر الدوحة، جامعة قطر ،مركز الوثائق والدراسات

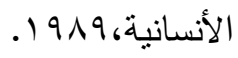

• (- مجيد محمد الأنصاري وأخرون، مبادئ المحاصيل الخقلية ،دار المعرفة ،طا ا، .91 ا. 1ا- مكي علوان الخفاجي وفيصل عبد الهادي المختار، إنتاج الفاكهة والخضر، بيت

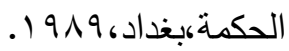

r ا- مكي علوان الخفاجي وأخرون ،الفاكهة المستديمة الخضرة ،مطبعة التعليم العالي،بغداد، ـ 199 . r ا - محمد هاشم البرقوقي ويوسف امين ولي ،الفاكهة أساسيات الإنتاج ،دار الهناللطباعة، 1907 .

ع ا- - محمد علي باشا ،أساسيات زراعة الفاكهة ،دار المطبوعات الجديدة ،الإسكندرية ،بدون ناريخ • 10- عبد اللطيف رحيم حسن وأخرون ،الفاكهة المستديمة ،الموصل ،دار الكتب للطباعة والنشر بجامعة

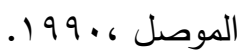

\section{(9)}


17 - عبد الجبار البكر ،مدى انتشار النخيل في العالم، مجلة الزراعة العراقية،المجلد ا،هجا، 1901 . IV عبد الجبار البكر ، نخلة التمور "ماضيها وحاضرها والجديد في زراعتها وصناعتها وتجارتها "،مطبعة

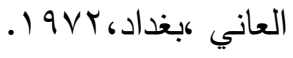

1 1- عبد الوهاب الدباغ، النخيل والتمور ،مجلة الأستاذ كلية التربية، جامعة بغداد، المجلد با ،العددان

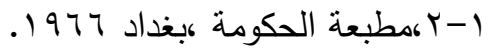

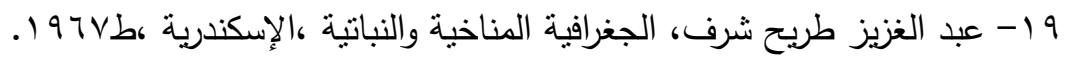

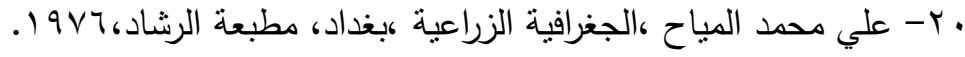
آ- علي حسين الثلش وعبد علي الخفاف، الجغرافية الحياتية ،وزارة التعليم والبحث العلمي ،هطبعة

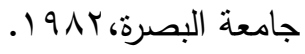
Yr- علي حسين الثلش، اثز الحرارة المتجعة على نمو ونضج المحاصيل الزراعية في العراق، الجمعية الجغرافية الكويتية ،الجامعة الكويتية،عددها ال7، ع191 الـ

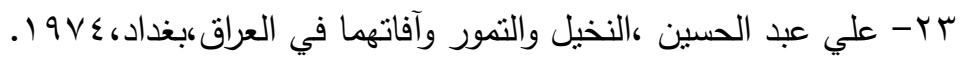
ع ז- صالح عاتي جاسم، تطور انتاج التمور في العراق وصناعتها وتجارتها (901-1911)،رساله ماجستير "غير منشورة" ،جامعة بغداد-كلية التربية الأولى، ـ 199 . هץ- قيس جميل عبد المجيد وعلي عبيد الحجيري، النخيل والتمور، وزارة التعليم العالي والبحث العلمي، هيئة المعاهد الفنية ،دار الحكمة للطباعة والنشر كبغداد، ـ99 19. ؟Y - فاتن خالد عبد الباقي، ظواهر طبقات الجو العليا وأثرها في تثكيل وصياغة مناخ العراق، أطروحة

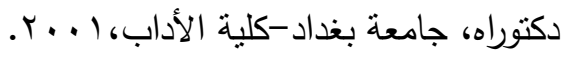

V V رياض عبد اللطيف ،الماء في حياة النبات، وزارة التعليم العالي والبحث العلمي ،جامعة

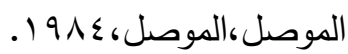

وزارة الزراعة، الهيئة العامة لزراعة المنطقة الجنوبية شعبة الدراسات بيانات غير منشورة ،با.ب. 29- A.C. Hildreth , J.R. Mage ness and Johan Michelle effects of climatic factors on growing plants climate and man, year book of Agriculture ,1941.p:393.

\section{pqr}


30-D.R.M.Smoky and A.M. Hubert, economic gropes vol. 11new York.1950.p:36.

31-Joseph. Evan Riper, Mans physical world, MC Grow Hill Book, New York.1971.p:48. 